\title{
BMJ Open Statistical projection methods for lung cancer incidence and mortality: a systematic review
}

\author{
Xue Qin Yu, ${ }^{\oplus 1,2}$ Qingwei Luo, ${ }^{\oplus 1}$ Suzanne Hughes, ${ }^{1}$ Stephen Wade, ${ }^{1}$ \\ Michael Caruana, ${ }^{1}$ Karen Canfell, ${ }^{1,2,3}$ Dianne L O'Connell ${ }^{1,2,4}$
}

To cite: Yu XQ, Luo Q, Hughes S, et al. Statistical projection methods for lung cancer incidence and mortality: a systematic review. BMJ Open 2019;9:e028497. doi:10.1136/ bmjopen-2018-028497

- Prepublication history and additional material for this paper are available online. To view these files, please visit the journal online (http://dx.doi. org/10.1136/bmjopen-2018028497).

$\mathrm{XQY}$ and $\mathrm{QL}$ contributed equally.

Received 11 December 2018 Revised 05 June 2019 Accepted 30 July 2019

A Check for updates

C Author(s) (or their employer(s)) 2019. Re-use permitted under CC BY-NC. No commercial re-use. See rights and permissions. Published by BMJ.

${ }^{1}$ Cancer Research Division, Cancer Council NSW, Sydney, New South Wales, Australia ${ }^{2}$ The University of Sydney School of Public Health, Faculty of Medicine and Health, The University of Sydney, Sydney, New South Wales, Australia

${ }^{3}$ Prince of Wales Clinical School, University of New South Wales, Sydney, New South Wales,

Australia

${ }^{4}$ School of Medicine and Public Health, University of Newcastle, Newcastle, New South Wales, Australia

Correspondence to

Dr Qingwei Luo;

qingweil@nswcc.org.au

\section{ABSTRACT}

Objectives To identify and summarise all studies using statistical methods to project lung cancer incidence or mortality rates more than 5 years into the future.

Study type Systematic review.

Methods We performed a systematic literature search in multiple electronic databases to identify studies published from 1 January 1988 to 14 August 2018, which used statistical methods to project lung cancer incidence and/ or mortality rates. Reference lists of relevant articles were checked for additional potentially relevant articles. We developed an organisational framework to classify methods into groups according to the type of data and the statistical models used. Included studies were critically appraised using prespecified criteria.

Results One hundred and one studies met the inclusion criteria; six studies used more than one statistical method. The number of studies reporting statistical projections for lung cancer increased substantially over time. Eighty-eight studies used projection methods, which did not incorporate data on smoking in the population, and 16 studies used a method which did incorporate data on smoking. Age-period-cohort models (44 studies) were the most commonly used methods, followed by other generalised linear models (35 studies). The majority of models were developed using observed rates for more than 10 years and used data that were considered to be good quality. A quarter of studies provided comparisons of fitted and observed rates. While validation by withholding the most recent observed data from the model and then comparing the projected and observed rates for the most recent period provides important information on the model's performance, only 12 studies reported doing this. Conclusion This systematic review provides an upto-date summary of the statistical methods used in published lung cancer incidence or mortality projections. The assessment of the strengths of existing methods will help researchers to better apply and develop statistical methods for projecting lung cancer rates. Some of the common methods described in this review can be applied to the projection of rates for other cancer types or other non-infectious diseases.

\section{INTRODUCTION}

Lung cancer has been the most commonly diagnosed cancer in the world for several decades and is the leading cause of cancer

\section{Strengths and limitations of this study}

- This is the first systematic review summarising statistical methods used in projecting lung cancer incidence or mortality rates over the past three decades.

- The review was conducted according to the published guidelines.

- Using predefined assessment criteria and a standardised data extraction form resulted in a high level of agreement in the data extractions performed by two independent reviewers.

- The review provided theoretical and practical information, including a comprehensive summary of the methods and relevant software.

- Meta-analysis was not possible due to the wide variation in study populations and time periods used in the projections.

deaths worldwide, accounting for nearly $20 \%$ of all cancer deaths. ${ }^{1}$ Reliable projections of future patterns of lung cancer incidence and mortality are, therefore, of importance for the planning of health service requirements and the management of healthcare resources. $^{2}{ }^{3}$ Given the well-documented association between tobacco smoking and lung cancer risk, ${ }^{45}$ projections of lung cancer incidence and mortality are also important for evaluating the effectiveness of existing tobacco control programme and the forward projection of the potential impact of new evidence-based tobacco control strategies. $^{267}$ There have been a variety of statistical methods developed and reported in the literature for projecting cancer incidence or mortality rates. ${ }^{2}$ These methods range from assuming the current rate remains unchanged into the future, to a more complex class of statistical models of past trends such as ageperiod-cohort (APC) models, which may involve a range of assumptions, software and techniques.

Projecting future cancer incidence and mortality trends is always a complex exercise due to the changing risk factor profiles over 
time, and the long latency period between risk factor exposure and development of some cancers. ${ }^{8}$ For lung cancer in particular, projections can be inaccurate if any changes in past smoking behaviour are not accurately taken into account. ${ }^{23}$ Unfortunately, data on smoking behaviour are not always available with the requisite level of detail (eg, sex-age-specific data), so choosing and implementing an appropriate projection method largely depends on data availability and the purpose for the projections. ${ }^{8}$ Given the complexity involved in such projections, information on the available statistical methods, utilisation of these methods and further developments in this area are of particular interest to researchers working in this field. However, while some of these methods have been reviewed and evaluated, ${ }^{8-11}$ to our knowledge, there are currently no published systematic reviews of all statistical methods available for projecting lung cancer incidence or mortality rates.

Therefore, we carried out a methodological systematic review to identify and summarise published population-based studies that used statistical methods to project lung cancer incidence or mortality rates over the long term (eg, more than 5 years). The aim was to provide up-to-date and comprehensive information on the statistical methods that are available for projecting lung cancer rates. In doing so, our intention was to provide readers with an understanding of these various statistical methods, the availability of statistical software to implement these methods, and the utilisation of these methods in different circumstances, and to highlight the differences and similarities between methods.

\section{METHODS}

This systematic review adhered to the checklist presented in the Preferred Reporting Items for Systematic Reviews and Meta-Analyses. ${ }^{12}$ A protocol was developed for this review and is included as online supplementary resource 1.

\section{Patient and public involvement}

As this was a systematic review of statistical methods used to obtain lung cancer rate projections, no patients or public were involved.

\section{Literature search}

In August 2016, Embase, Medline and PreMEDLINE databases were searched using text terms and, where available, database-specific subject headings, for studies published since 1988, which used statistical methods to project lung cancer incidence and/or mortality. Searches for lung cancer-related terms were combined with searches for terms related to projection, forecasting and statistical models. Reference lists of relevant articles were checked for additional potentially relevant articles. In August 2018, Embase and Medline, including Epub Ahead of Print, In-Process and other Non-Indexed Citations databases, were searched for studies published from 2016 onwards using an updated search strategy, which aimed to capture all newly published articles. A complete list of the terms used is included in online supplementary resource 2 .

\section{Selection criteria}

Full inclusion and exclusion criteria are listed in table 1. Studies were included if they used a statistical method to project lung cancer incidence and/or mortality over a period greater than 5 years using population-based data and were published in English from 1 January 1988 to 14 August 2018. 'Statistical method' was defined as a method that analyses the observed data using traditional regression, correlation or other statistical summaries.

\begin{tabular}{|c|c|c|}
\hline Domain & Inclusion criteria & Exclusion criteria \\
\hline Study type & Population-based original research studies & $\begin{array}{l}\text { Any of: Editorial comment, literature review, case studies, } \\
\text { clinical trials, case-control studies. }\end{array}$ \\
\hline Study population & General population in any country & $\begin{array}{l}\text { Restricted to selected groups, that is, selected patients } \\
\text { with cancer or high-risk populations. }\end{array}$ \\
\hline Statistical method & $\begin{array}{l}\text { Uses a statistical method for the projection, } \\
\text { including studies, which used simulation } \\
\text { methods to estimate confidence intervals, that } \\
\text { is, Bayesian technique }\end{array}$ & $\begin{array}{l}\text { Uses mathematical models, which generate outcomes } \\
\text { based on a proposed theoretical model of the disease's } \\
\text { natural history. }\end{array}$ \\
\hline $\begin{array}{l}\text { No of years } \\
\text { projected }\end{array}$ & $\begin{array}{l}\text { Reports long-term projections, that is, greater } \\
\text { than } 5 \text { years }\end{array}$ & $\begin{array}{l}\text { Does not report projections of lung cancer rates, that is, } \\
\text { only explains past trends, or reports projections less than } \\
\text { or equal to } 5 \text { years. }\end{array}$ \\
\hline $\begin{array}{l}\text { Time of } \\
\text { publication }\end{array}$ & $\begin{array}{l}\text { Published from } 1 \text { January } 1988 \text { to } 14 \text { August } \\
2018\end{array}$ & Published before 1988. \\
\hline Language & English & Language other than English. \\
\hline
\end{tabular}




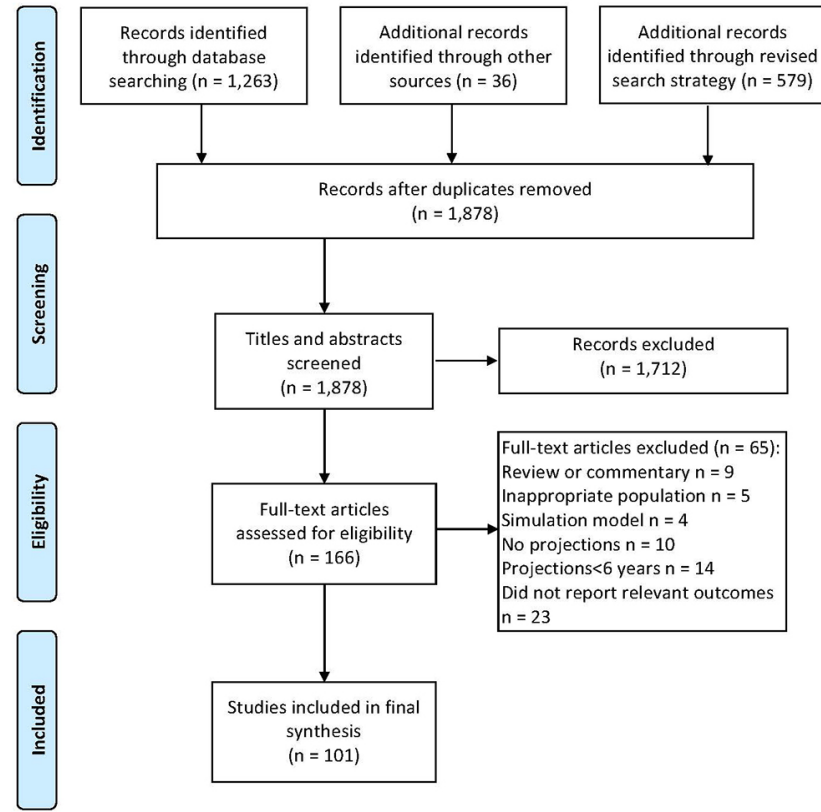

Figure 1 PRISMA flow chart of study selection process. PRISMA, Preferred Reporting Items for Systematic Reviews and Meta-Analyses.

'Projection' was defined as the use of data including the whole or part of the observed data to forecast lung cancer incidence or mortality rates beyond the time period covered by the data included in the statistical models. Mathematical models, which generate outcomes based on a proposed theoretical model of the disease's natural history, were not included in this review.

\section{Application of selection criteria}

The literature search and the review followed the stages described in figure 1. After removing duplicates, 1878 studies were retained for screening. One author (SH) screened the titles and abstracts against the inclusion criteria to exclude articles that were clearly irrelevant. The main reason for exclusion of papers at the screening stage was that the studies did not report on lung cancer incidence or mortality. Others were excluded because they used mathematical methods rather than being population-based studies. Further studies were excluded because they were an editorial commentary or literature review. After the screening process, a total of 166 studies were eligible for full-text review.

Full-text articles were independently reviewed and assessed for inclusion by two authors (XQY and QL) and a total of 101 studies were retained for final inclusion (92\% agreement). Disagreements were discussed and if an agreement could not be reached the study was assessed for inclusion by a third reviewer (DLO). Excluded studies and the reasons for exclusion are listed in online supplementary resource 3 . The main reasons for exclusion of studies at this stage were that they did not report lung cancer rates separately or the projections were for fewer than 6 years.

\section{Critical appraisal}

As the purpose of this methodological review was to provide an overview of statistical methods, and the projections of lung cancer rates were conducted in different populations and over different time periods, no meta-analysis was possible and specific projection results were not compared or analysed in this review. Therefore, the risk of bias evaluation of the included studies was not applicable.

The methodological quality of the studies was independently assessed by two reviewers using prespecified criteria (table 2): quality of the data source, length of period covered by the observed data, availability of software information, model fitting and validation. Validation provides information on the performance and reliability of the projection model and can be undertaken by withholding the most recent observed data from the model fitting and then comparing the projected rates for those years with the actual observed values. ${ }^{7}$ As the use of scales for assessing study quality is discouraged in Cochrane reviews ${ }^{13}$ and meta-analyses,${ }^{14}$ as the calculation of an overall score inevitably involves assigning (often arbitrary) weights to the quality criteria being assessed. It is difficult to justify the weights used and it has been shown that the overall quality score is not a reliable assessment of the study's validity. ${ }^{13}$ Moreover, each method included in this review has its own merits and limitations, and depending on specific circumstances may be more or less reliable or relevant. Therefore, an overall score for the methodological quality of each study was not provided.

\section{Data extraction}

For each included study, two reviewers (XQY and QL) independently extracted details of the study including data sources, study population, year of publication, observed data period for the projections, statistical methods and software used, and whether the method incorporated information about smoking patterns, which is the main risk factor for lung cancer. The extracted data were collected using a standardised form (see online supplementary resource 4), which was pilot tested using 10 studies. Any differences between the two reviewers were discussed and when agreement could not be reached the studies were assessed by a third reviewer (DLO). The overall agreement between the two reviewers was $91.6 \%$.

The selection of an appropriate statistical method for projecting cancer rates is largely restricted by the quality and availability of cancer data, which is generally better in more developed countries. ${ }^{15}$ The Human Development Index (HDI), developed by the United Nations, ${ }^{16}$ is a summary measure of life expectancy, education and gross domestic product per head of population. We, therefore, recorded HDI ranking for each of the study populations, so that we could describe the distribution of projections methods used according to the country's level of development. 
Table 2 Prespecified criteria for assessing studies included in this review

\begin{tabular}{lll}
\hline Criterion & Yes & No or not clear \\
\hline $\begin{array}{ll}\text { Strengths } \\
\geq 10 \text { years observed data }\end{array}$ & Observed data period reported $\geq 10$ years. & $\begin{array}{l}\text { Observed data period reported }<10 \text { years, } \\
\text { or there is insufficient information to make } \\
\text { an assessment. }\end{array}$
\end{tabular}

Good quality data source Data source reported, and the majority of observed data used are included in IARC Cancer in Five Continents, or with high population coverage as stated in WHO database.
Data source reported but the majority of observed data used are not included in IARC Cancer in Five Continents, or with low population coverage as stated in WHO database, or there is insufficient information to make an assessment.

Reports both model estimates and observed data for Does not report both model estimates the period used for model fitting. and observed data for the period used for model fitting.

Does not provide validation using observed data.

\begin{tabular}{|c|c|}
\hline $\begin{array}{l}\text { Validated projections } \\
\text { using observed data }\end{array}$ & $\begin{array}{l}\text { The model was validated by excluding data for the } \\
\text { most recent years from the model fitting, and then } \\
\text { comparing the projected rates for those years with } \\
\text { the observed data. Provides both model projections } \\
\text { beyond the period included in model fitting and a } \\
\text { comparison with the observed data for the same } \\
\text { period. }\end{array}$ \\
\hline
\end{tabular}

Advantage
Provided software information

\section{Software information was described or referenced. Software information not provided.}

IARC, International Agency for Research on Cancer; WHO, World Health Organization.

\section{Classification of statistical methods}

In order to summarise the differences and similarities between the methods reported, we developed an organisational framework to classify methods into groups according to both the type of observed data used and the statistical models reported (figure 2). As tobacco exposure is well known to be the most significant risk factor for lung cancer ${ }^{4}$ and can be used as an important predictor for lung cancer incidence and mortality, we first divided the studies into two large categories according to whether or not they included data on smoking in the projection method. For each category, we then subdivided studies into groups according to the projection method used. Methods not incorporating data on smoking in the population were grouped as either: (1) APC models, a special form of generalised linear model (GLM), which includes age, period and cohort components, (2) other GLMs, where the number of cases (deaths) or the logarithm of this was modelled as a linear or non-linear function of the explanatory factors using the logarithm of the population size as an offset, with Poisson or negative binomial distribution and (3) present state method (eg, assumes that the age-specific rates in the future will be the same as the most recent observed rates, or assumes a constant annual rate of change as observed in a selected time period). Methods incorporating data on smoking were grouped into: (1) GLMs with a smoking variable as one of the covariates, (2) APC models that included an effect for smoking, (3) projections adjusted for the smoking attributable fraction (SAF) and (4) other methods (including all methods that do not use detailed historical cancer data or do not include detailed data on smoking). More detailed descriptions of each of these methods are provided in online supplementary resource 5 .

\section{RESULTS}

A total of 101 eligible studies were included (table 3). All these studies are ecological studies that used single year or 5-year aggregated population incidence or mortality data, or are based on cancer rates reported in the literature. Table 4 shows the study characteristics grouped according to the method used for the projections. Eightyeight studies used projection methods not incorporating data on smoking, ${ }^{12917-101} 16$ studies used a method incorporating data on smoking, ${ }^{3} 7334142102-112$ and 6 studies used multiple methods. ${ }^{18} 3336414262$ Overall, APC models were the most commonly used method to project lung cancer rates (44 studies used this method), ${ }^{2}{ }^{17-58}$ and other GLMs were the next most commonly used (35 studies). ${ }^{18} 3659-89100101$ Only 12 studies used the present state method by assuming that the average cancer rates in the most recent years will remain constant into the future. ${ }^{16290-99}$ Of the 16 studies incorporating data on smoking, eight studies directly used GLMs with a variable reflecting detailed historical smoking-related behaviour as one of the covariates included. ${ }^{3733103106108111112}$ These variables included number of cigarettes consumed and 


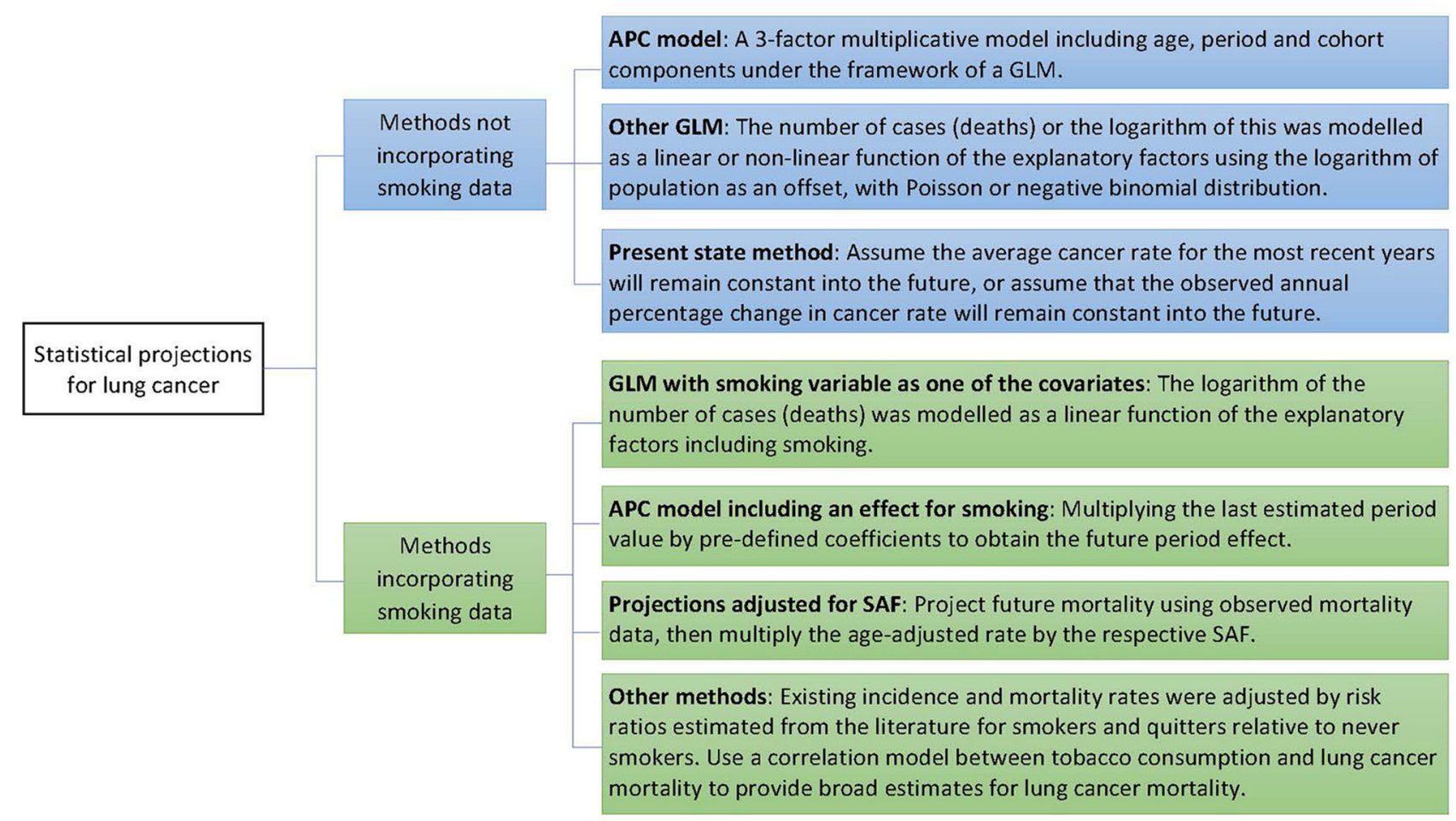

Figure 2 Organisational framework to categorise methods for lung cancer mortality projections. APC, age-period-cohort; GLM, generalised linear model; SAF, smoking attributable fraction.

average tar content, ${ }^{3} 733$ smoking prevalence, ${ }^{111}$ number of years of smoking ${ }^{106112}$ and smoking intensity. ${ }^{103108}$ Two studies used APC models and predefined coefficients based on recent trends in smoking prevalence and tar content to adjust the estimates for the period parameter. ${ }^{41}{ }^{42}$ Two studies made projections adjusted for the SAF, which required limited data on smoking behaviour, ${ }^{102} 107$ and the remaining four studies used other methods, which required limited data on both cancer rates and smoking behaviour. 104105109110

The majority of models were developed using more than 10 years of observed data that was considered to be good quality, that is, incidence data included in the Cancer Incidence in Five Continents series ${ }^{15}$ or mortality data from a source considered by WHO to have a high population coverage. ${ }^{113}$ Most studies provided projections for 10 years or more, and the proportion of studies providing projections for more than 19 years was higher for studies using methods incorporating data on smoking $(50.0 \%)$ than for studies using methods which did not incorporate smoking patterns $(18.2 \%)$. Only $25.7 \%$ of the studies provided comparisons of fitted and observed rates and $11.9 \%$ of the studies reported validation of the projection model using observed data.

The numbers of studies by publication period and by the country's HDI rank are presented in figure 3. The number of publications increased substantially over time, especially the number of studies using APC models, which more than tripled in the most recent period (2008-2018) compared with 1998-2007. The majority of the articles included in this systematic review used data from countries with very high or high HDI including studies from the USA, Europe and Australia, 16 studies used data from countries in medium or low HDI groups including studies from China and India, and 22 studies used data from multiple countries.

The statistical software packages used by method and year of publication are shown in figure 4. Among the studies using APC models, the most commonly used software package was Nordpred ( $\mathrm{R}$ package developed by Harald Fekjær and Bjørn Møller, Cancer Registry of Norway) ${ }^{1038}$ and most of these studies were published in recent years. GLIM (Oxford, UK) ${ }^{114}$ was the second most commonly used software for APC modelling, but it was mainly used in the earlier years, with the latest study published in 2000. ${ }^{45}$ Special software WinBUGS (Cambridge, UK), ${ }^{115}$ INLA (R package developed by Rue and Martino, Department of Mathematical Sciences NTNU, Norway) ${ }^{116}$ or BAMP (Institute of Biomedical Engineering, Imperial College, London, UK) ${ }^{117}$ were used for studies employing Bayesian methods. $2022252631-334885$ Among studies using other GLMs, Joinpoint (National Cancer Institute, USA) ${ }^{118}$ and Stata ${ }^{119}$ were the two most commonly used software packages. Most studies using the present state method did not mention which software was used. Nordpred, Stata, Joinpoint, SAS, ${ }^{120}$ other R packages and WinBUGS were the software program most commonly used in the recent time period. An overview of these software packages is provided in table 5. Each of these packages has different features and some are freely available to researchers. 


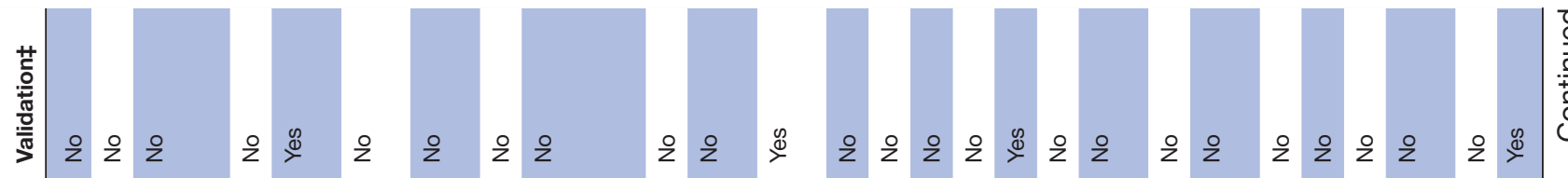

总

$\frac{8}{\frac{8}{2}} \frac{1}{8}$

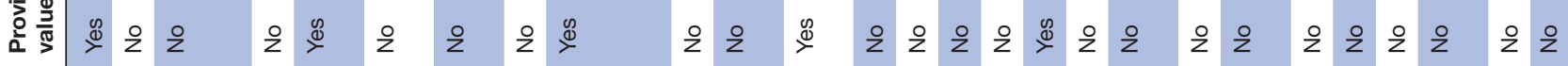
要.

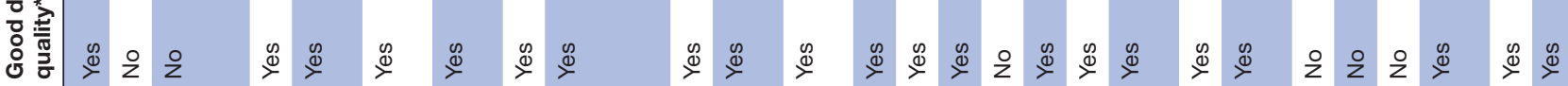

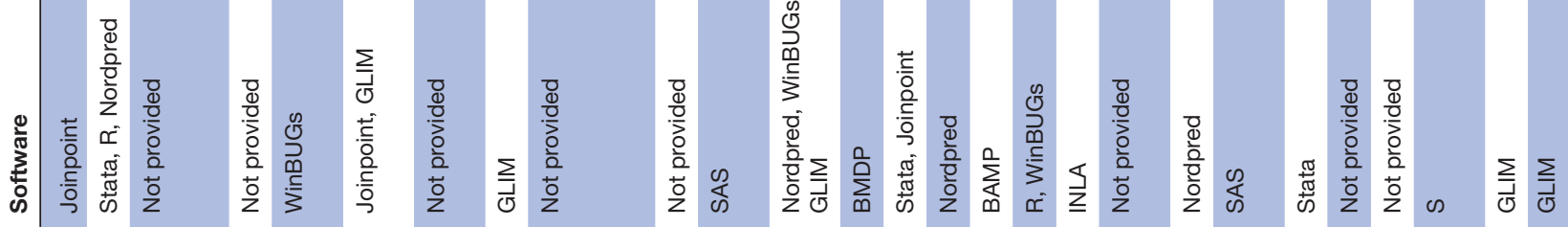

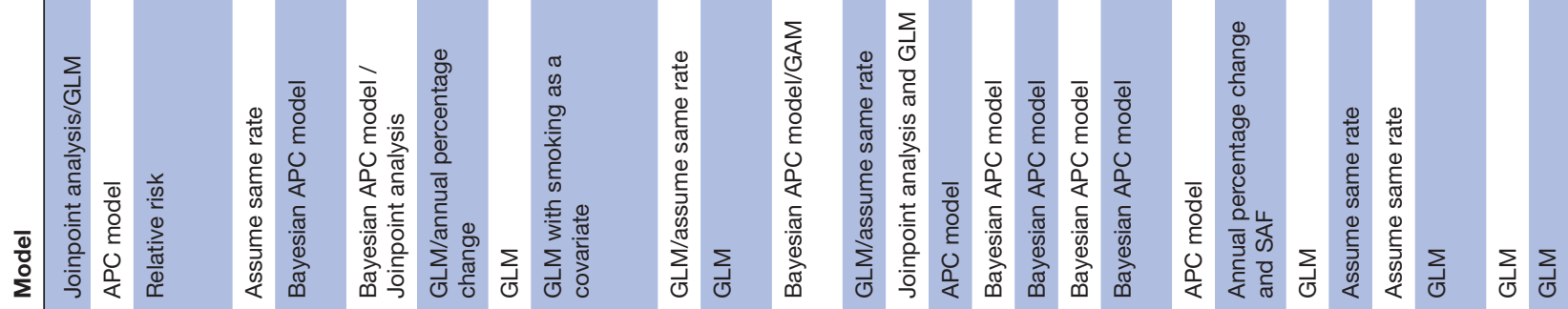

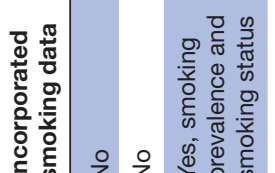

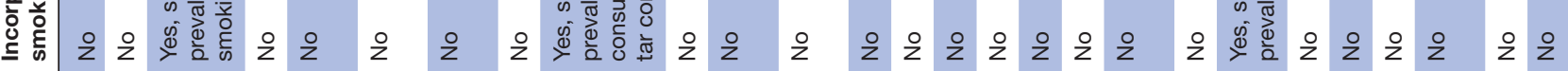

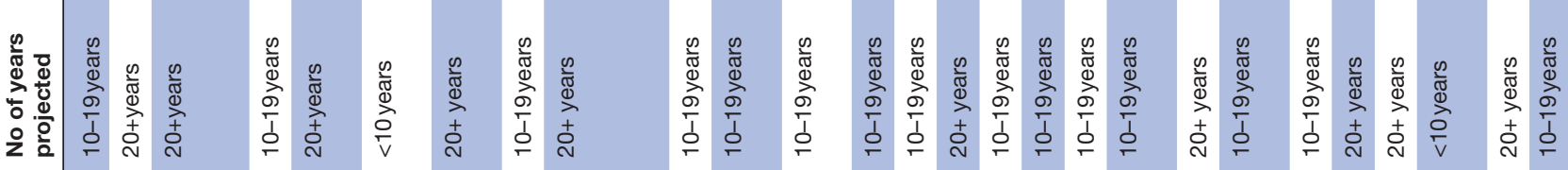

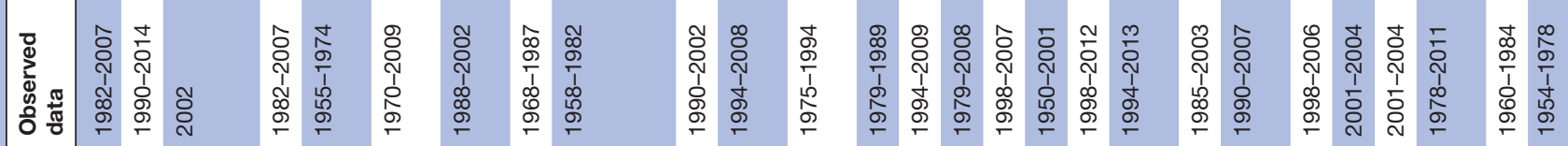

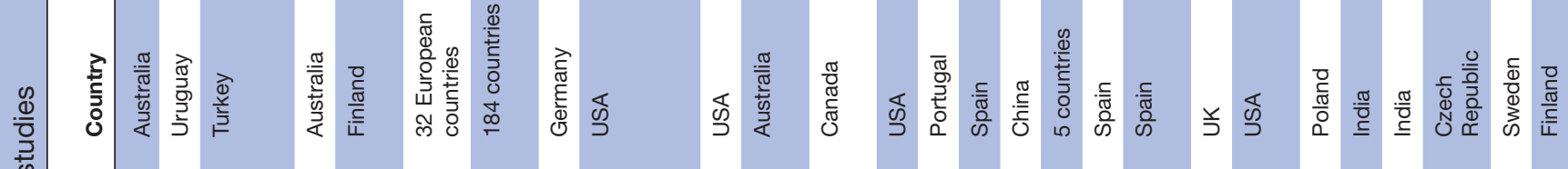

ठำ

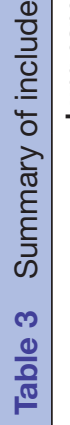

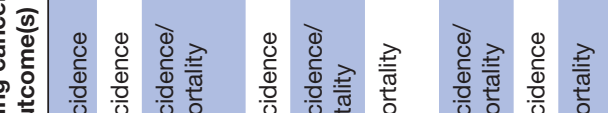

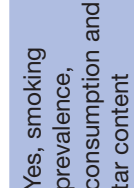

旁 范

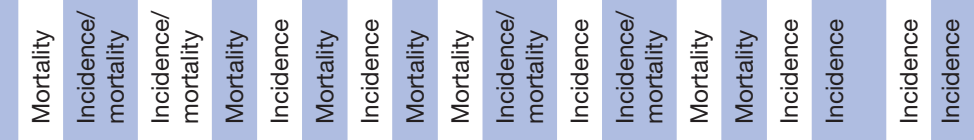

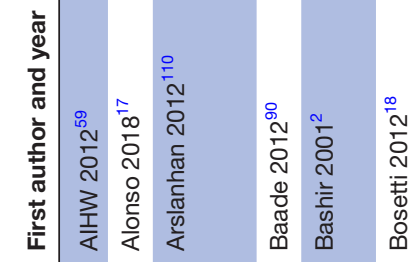

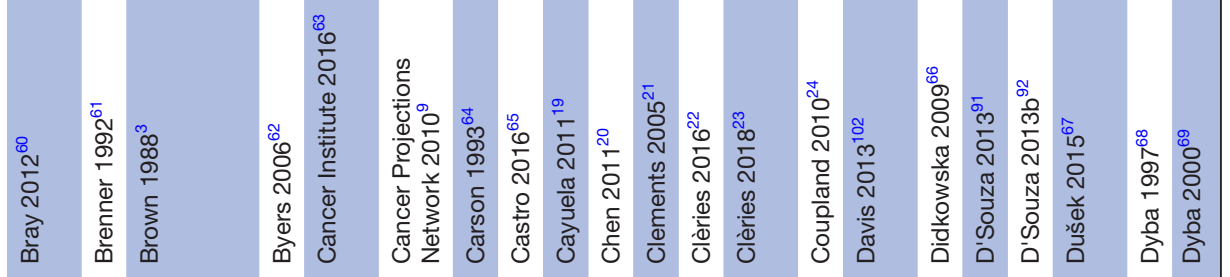


突

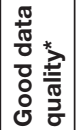

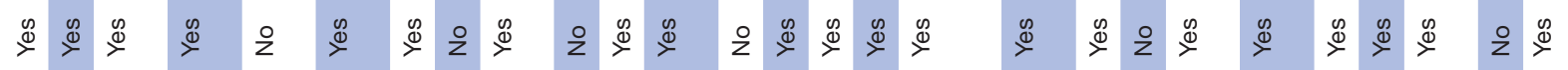

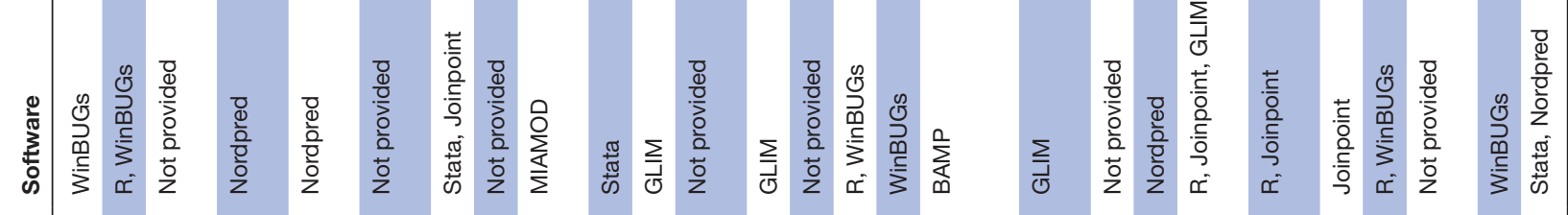

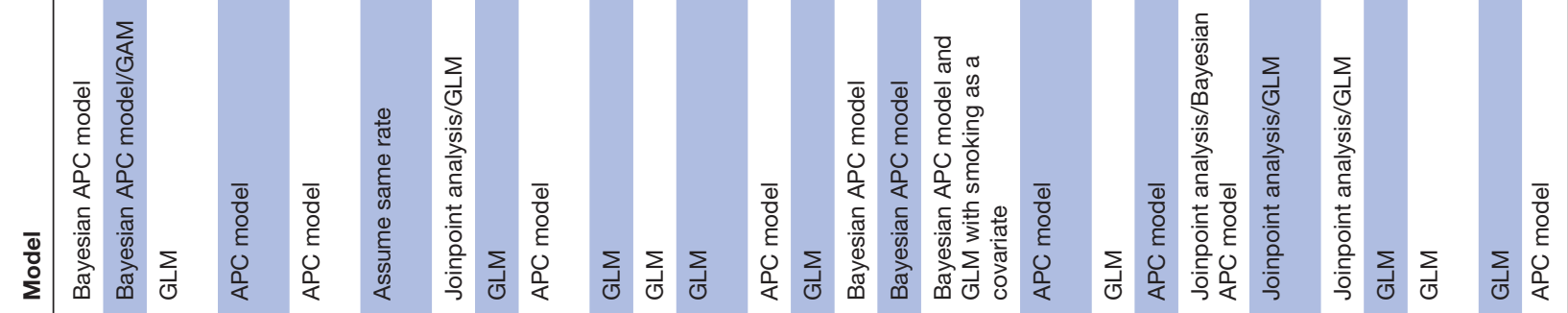

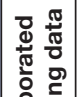

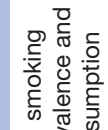

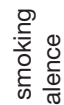

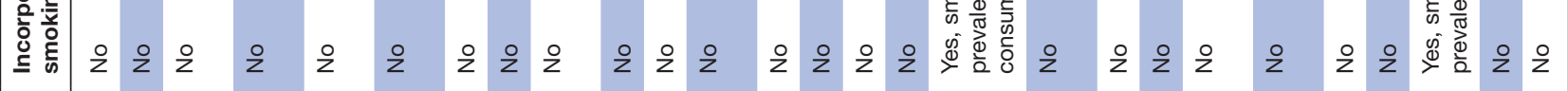

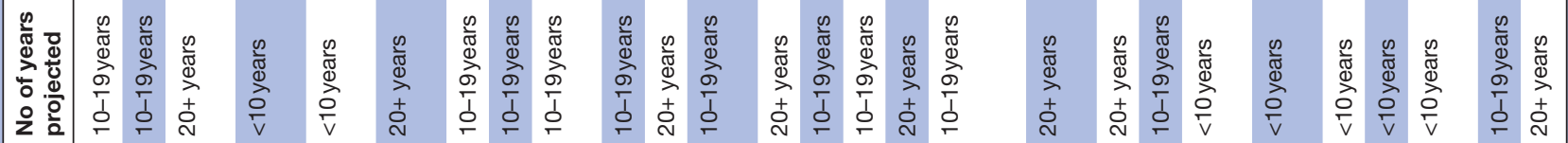

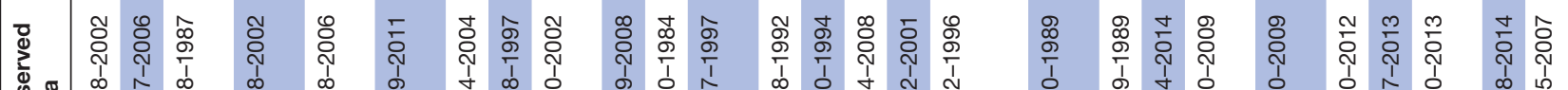

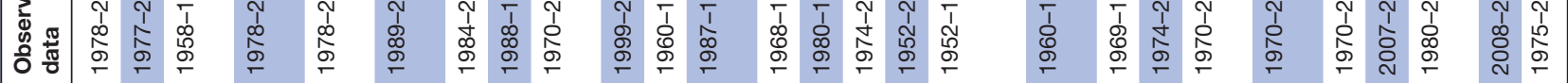

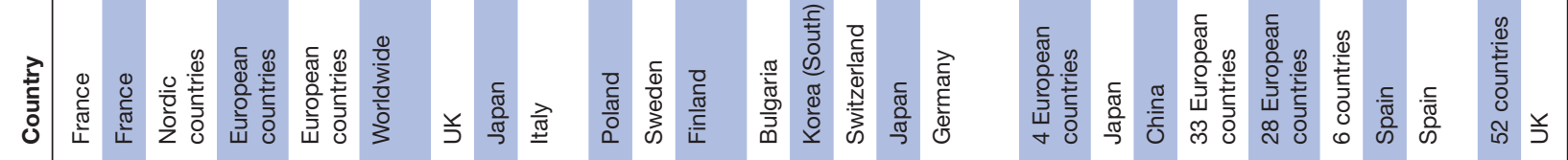

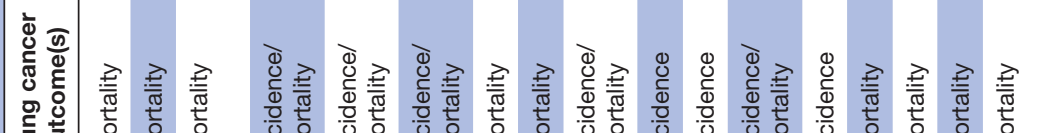

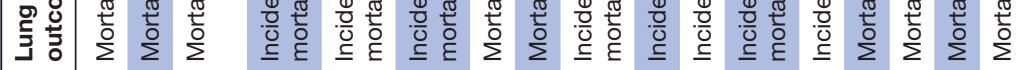

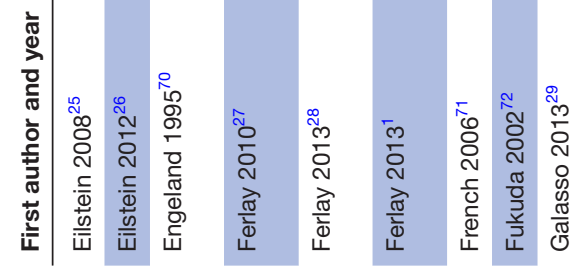

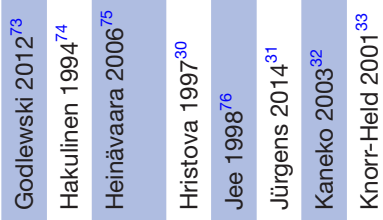

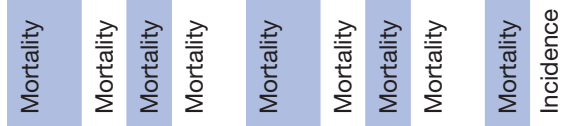




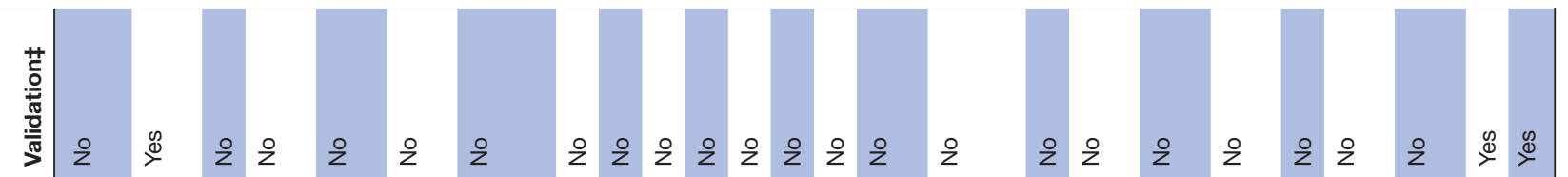

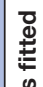

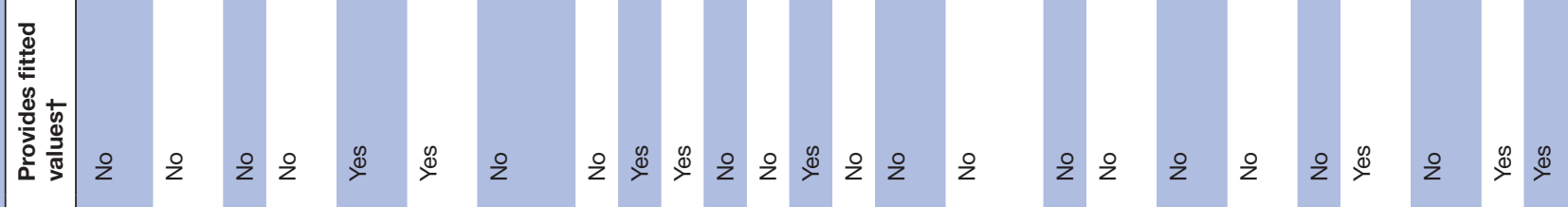

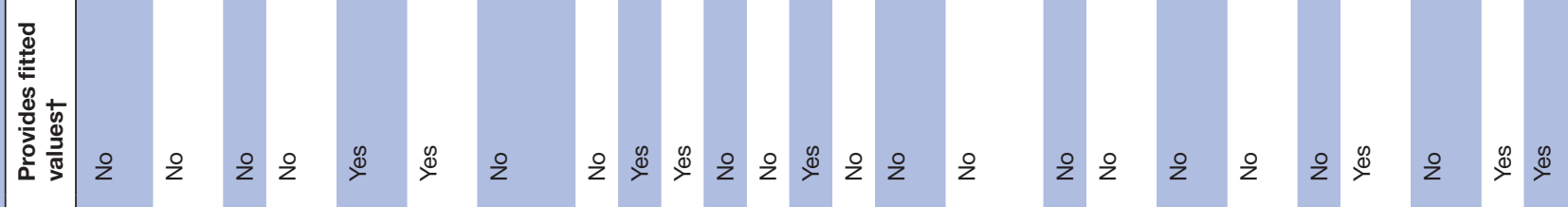

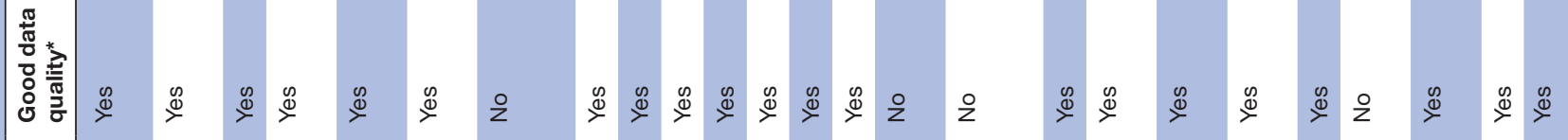

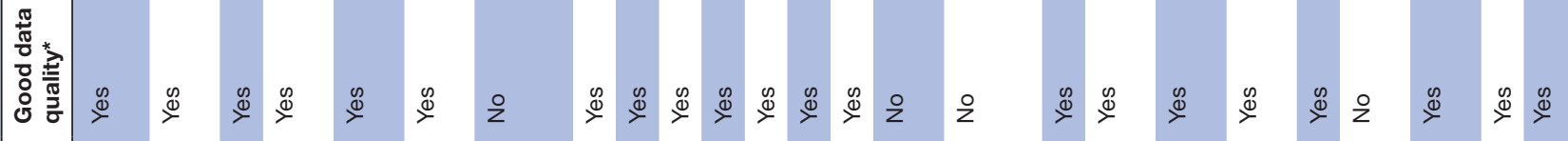

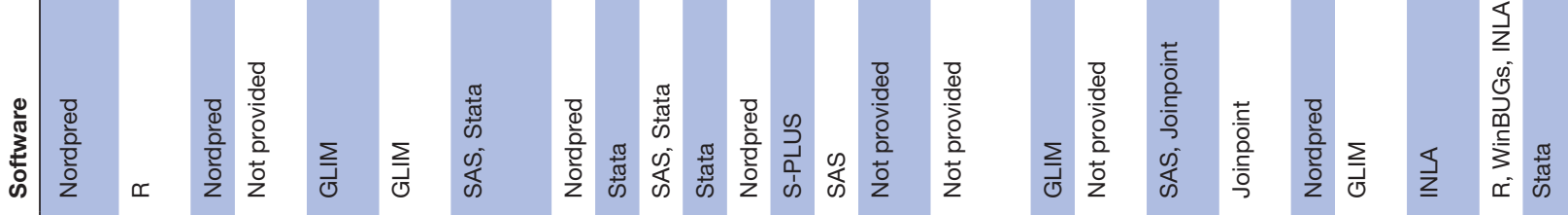

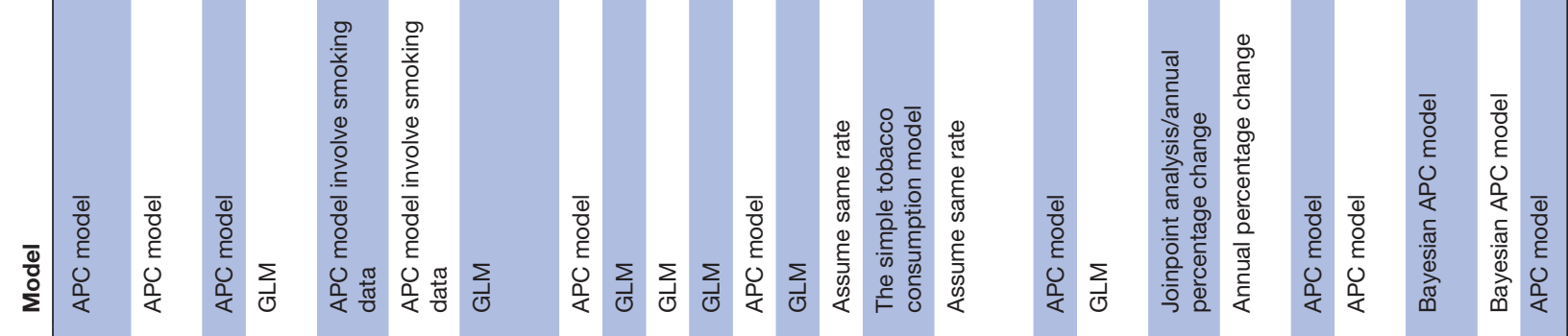

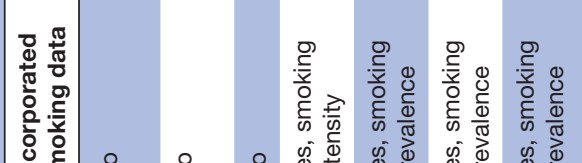

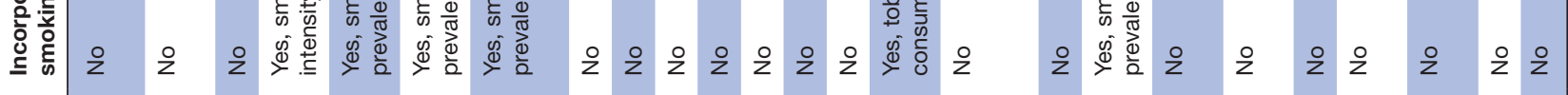

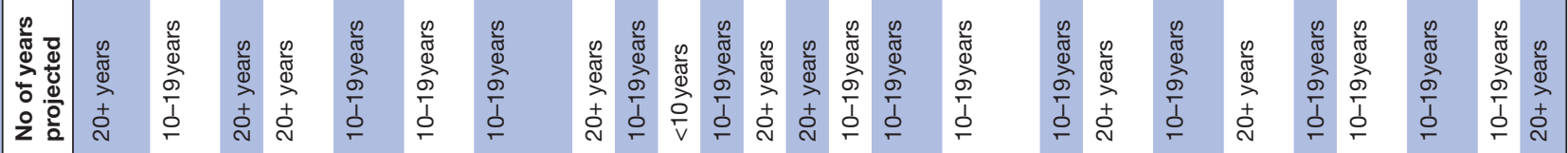

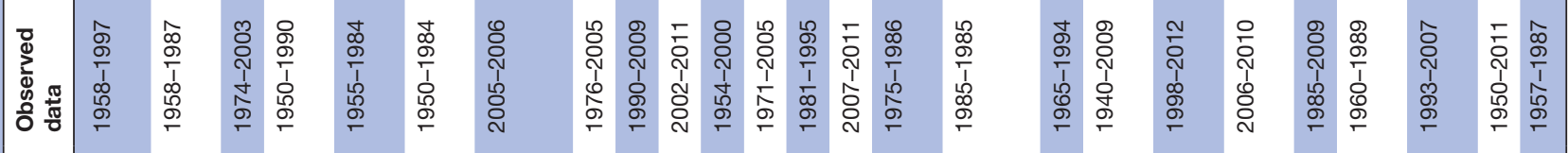

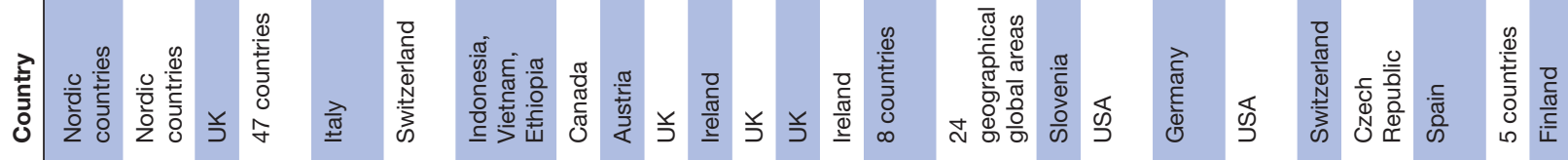

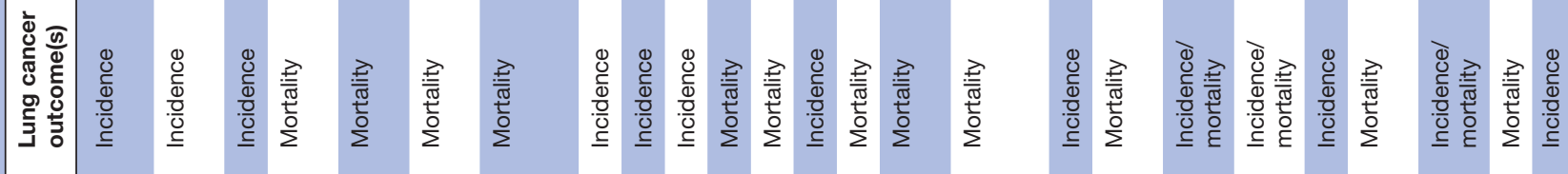




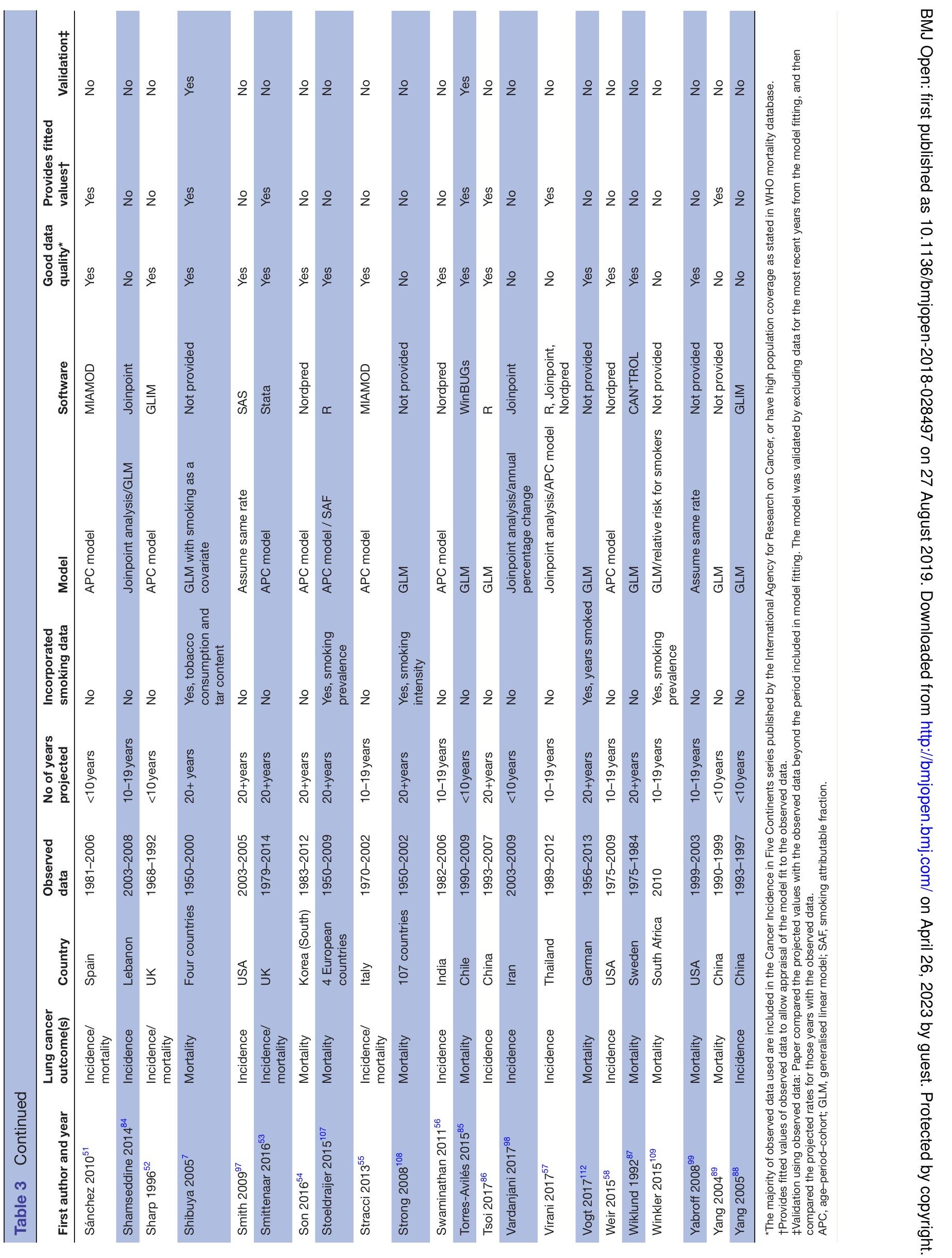




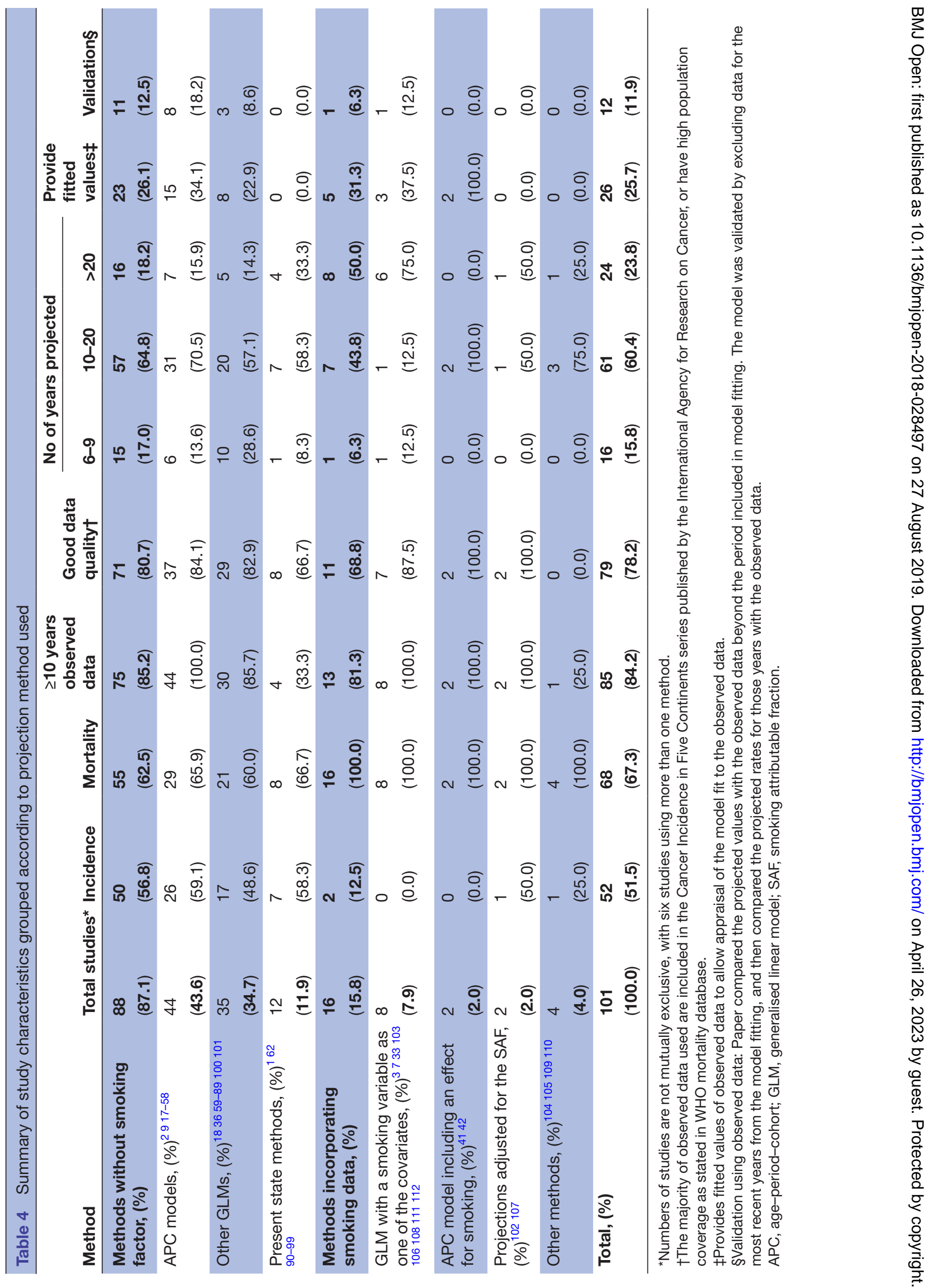


By year of publication

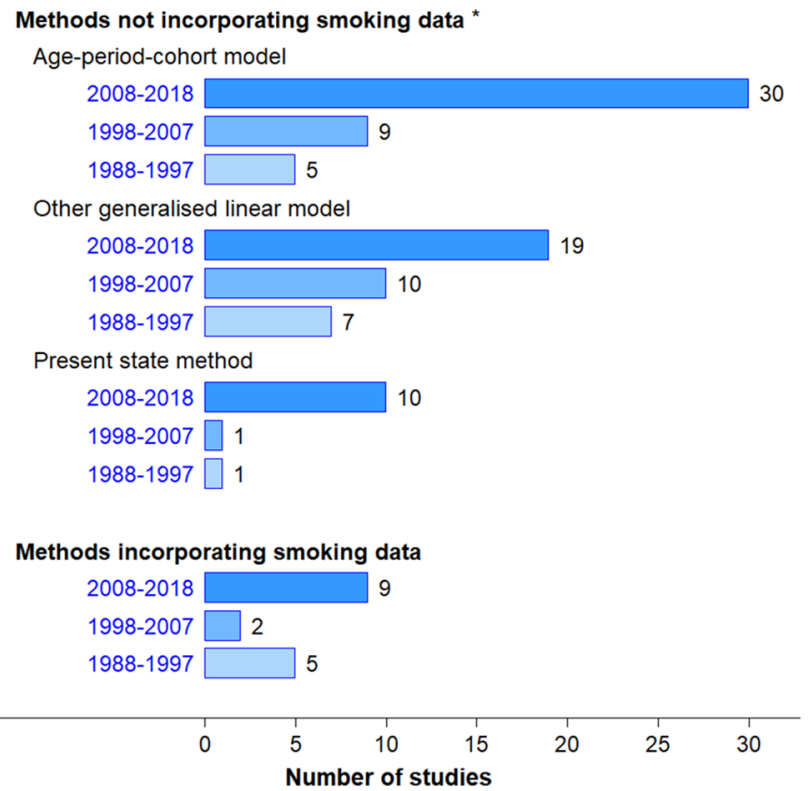

By rank of HDI of the country

Methods not incorporating smoking data *

Age-period-cohort model

$\begin{aligned} & \\ \text { Very high HDI } & \\ \text { High HDI } & \end{aligned}$

Medium or low HDI $\square 1$

Other generalised linear model

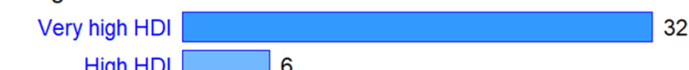

High HDI

32

Medium or low HDI $\square 2$

Present state method

Very high $\mathrm{HDI}$

High HDI $\square 3$

Medium or low HDI $\square 3$

Methods incorporating smoking data

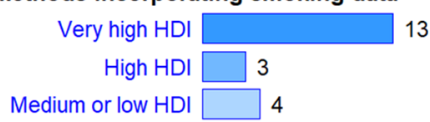

\begin{tabular}{llllllll}
\hline 0 & 5 & 10 & 15 & 20 & 25 & 30 & 35
\end{tabular}

Figure 3 Studies included by year of publication, 1988-2018 and level of human development of the country providing the data, stratified by method. *Six studies used more than one method, and 22 studies used data from multiple countries. HDI, Human development index.

\section{DISCUSSION}

This review highlights the scope and diversity of the statistical methods used to project lung cancer rates for the longer term, and provides a summary of the main methods used in studies conducted over the last three decades. These methods range from using a basic assumption that the current rate will remain unchanged into the future, to more complex statistical models involving a range of different assumptions, statistical techniques and software packages. We found that both lung cancer incidence and mortality projections were commonly based solely on past cancer trends, and only a limited number of studies incorporated smoking data in the projection models, most likely due to the scarcity of data on past

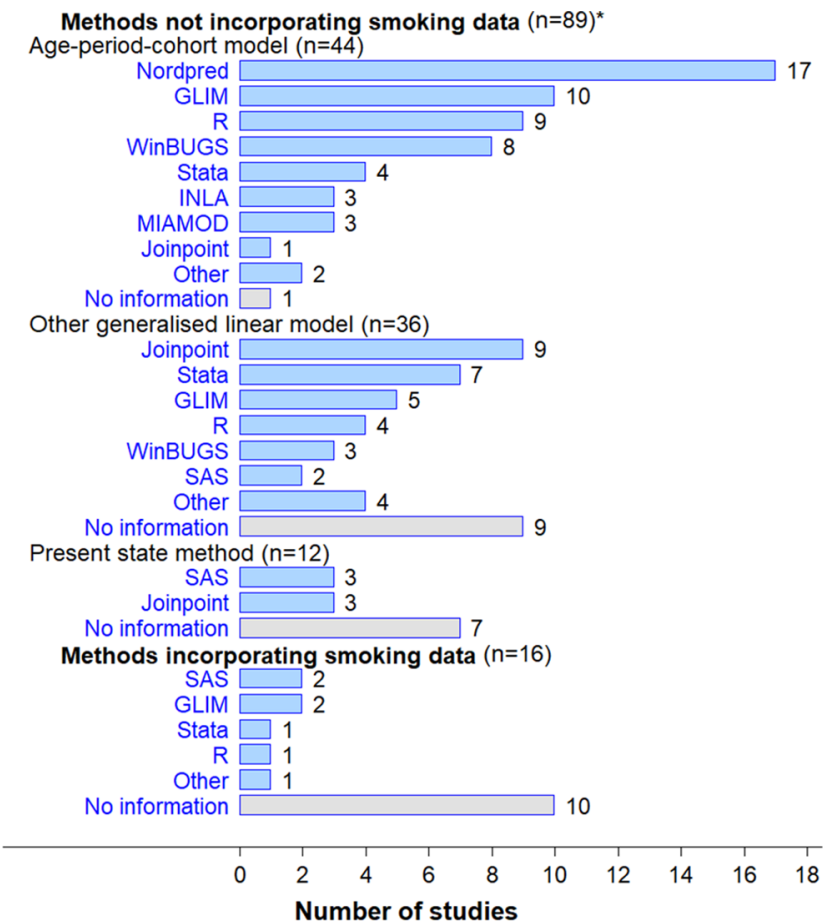

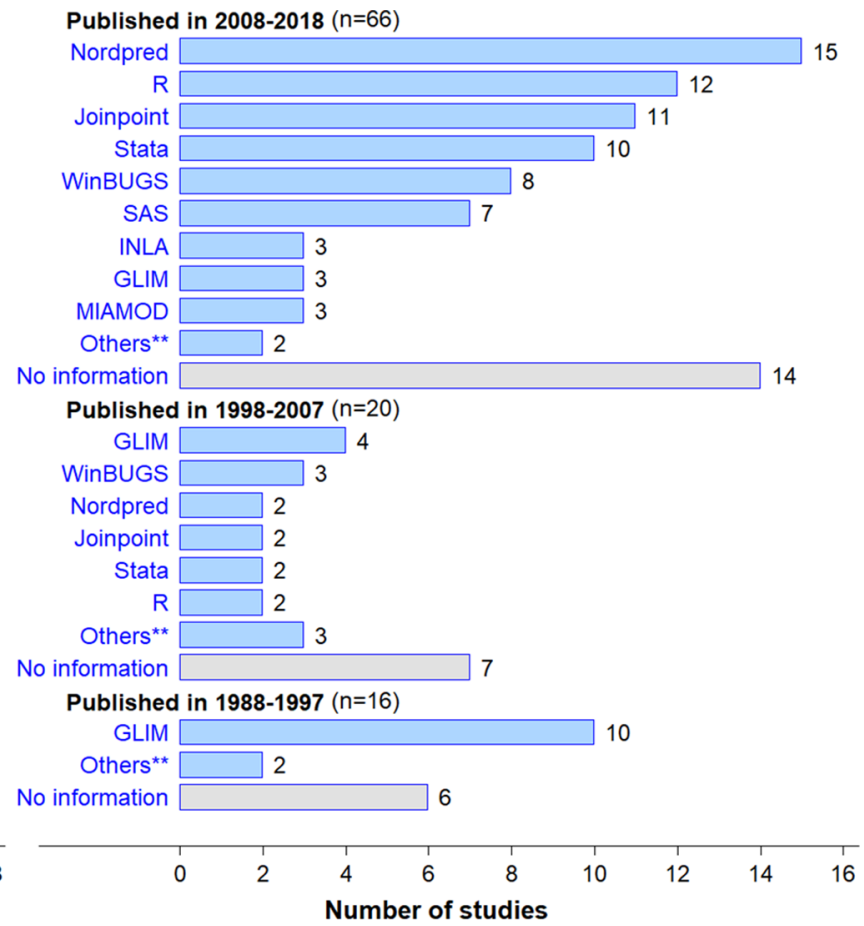

Figure 4 Statistical software packages used by method and year of publication. *Six studies used more than one method, 20 studies used more than one software package. ${ }^{* *}$ Others include BMDP, BAMP, S-Plus, S and Can ${ }^{\star}$ Trol. 


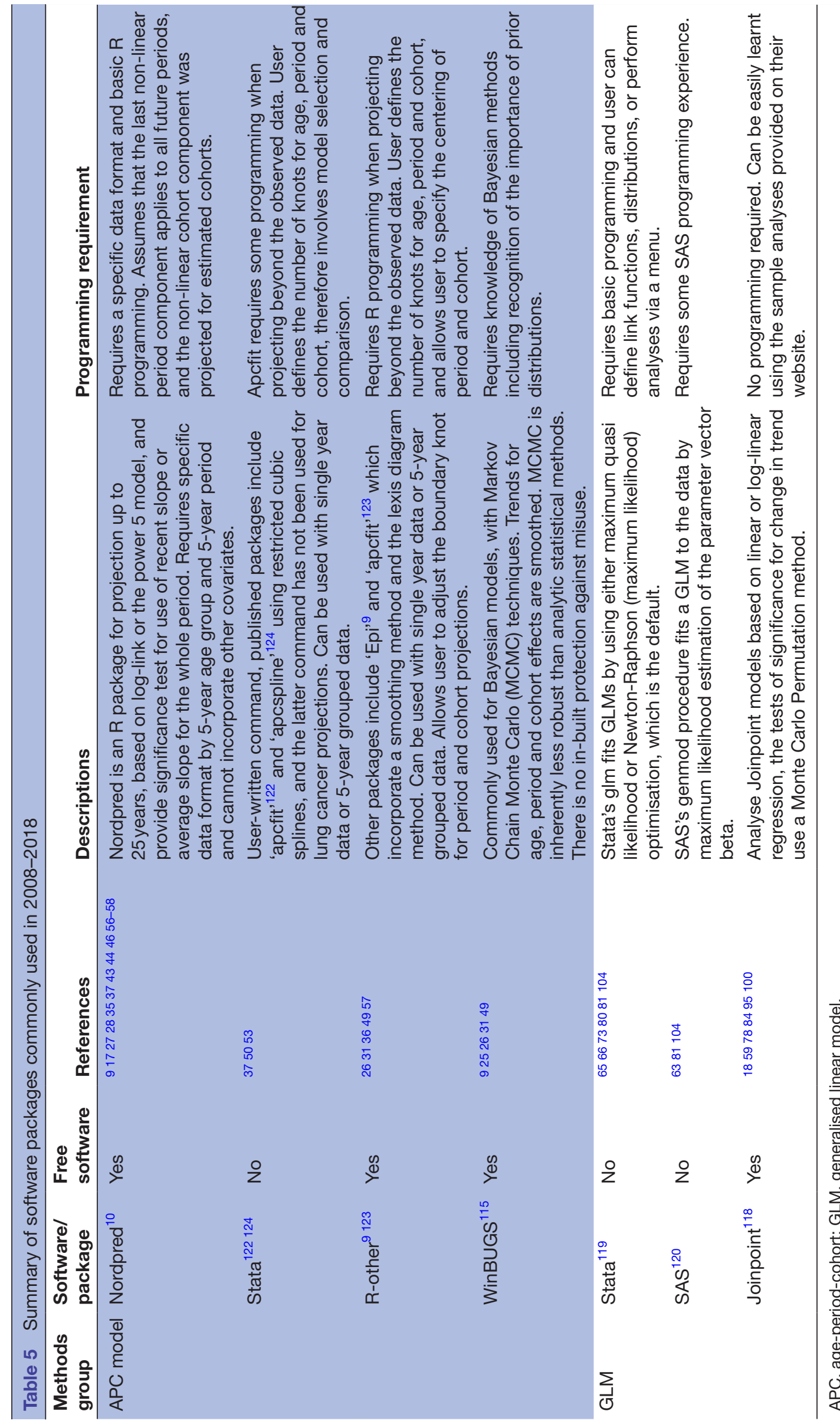


smoking behaviour in the population. ${ }^{21}$ Methods, which do not incorporate smoking data, are also generalisable to projections for other cancer types. We found that the number of studies reporting statistical projections for lung cancer increased substantially over time, and that the majority of these studies used good quality data from countries with a very high or high level of HDI.

The three-factor APC model was the most commonly used method for projecting lung cancer rates. This method does not require knowledge of aetiological factors ${ }^{25}$ as the period and cohort effects are considered to be surrogates for exposure to a range of risk factors. ${ }^{11}$ For example, period effects can reflect diagnostic and treatment factors, which lead to changes in disease incidence and survival across all age groups. ${ }^{11}$ On the other hand, the cohort effect may represent risk factors such as smoking behaviour that change from generation to generation. ${ }^{71106}$ This method is considered to be appropriate for long-term projections. ${ }^{10}$ However, due to the non-identifiability of the linear components of the age, period and cohort parameter estimates, there is no way to distinguish the period effect and the cohort effect. This non-identifiability issue for APC models can be addressed by introducing constraints to the time effects, however, the parameter estimates can be sensitive to the choice of constraint on period and cohort factors. ${ }^{3121}$ In addition, the APC model used in this context generally assumes that current and past trends continue into the future, and such an assumption would be questionable if any interventions have significant impacts on the cancer rates. Given the latency period between exposure to a cancer agent and development of some cancers, projections that are based on past trends may be inaccurate. ${ }^{8}$ Nonetheless, with the development of strategies to deal with the inherent non-identifiability problem in such models, the APC model has been implemented in various statistical software packages in recent years. ${ }^{102-124}$

In contrast to the APC model, other methods using GLMs do not include all three time components in the same model, making them less complicated to use. GLMs are more flexible and can be easily implemented using commonly available software including Stata, ${ }^{119}$ SAS, ${ }^{120}$ $\mathrm{R}$ and Joinpoint. The interpretation of the results from the standard GLM seems to be straightforward, and it can be extended to incorporate other factors. ${ }^{125}$ This method has been evaluated using Finnish Cancer Registry data and it was concluded that the GLM performed reasonably well for short-term (eg, 5 years) projections. ${ }^{125}$ However, GLMs may not be appropriate for long-term projections ( $>10$ years) as the model does not consider period and cohort effects at the same time. For example, a GLM without a cohort component may not be appropriate for cancer types where significant changes in risk factors have occurred, due to the lack of cohort-specific effects in the projections. ${ }^{125}$ On the other hand, a GLM without a period component will not be able to capture the changes in period effects for cancer types with screening programme or improvements in treatments over time. ${ }^{33}$ It is recommended that the potential significance of period and cohort effects should be examined and determined prior to implementing any projections using GLMs. ${ }^{9}$

The present state method is the simplest projection method, which projects future numbers of lung cancer cases or deaths by applying the average of the age-specific incidence/mortality rates observed in the most recent years to the projected future age-specific population estimates. The projection is based on a very strong assumption that the rates will remain constant over the projection period, which could be 20 or 30 years long. This method does not need special software, and it is a practical method to use when long-term historical data are not available. Although the validity of this assumption may not be realistic, especially for long-term projections, the results of present state projections can provide base assumptions from which to examine the impact of population growth and ageing on the cancer burden, and can provide a benchmark which is useful for evaluating the effect of cancer prevention or intervention activities.

Due to the association between tobacco smoking and lung cancer risk, ${ }^{45}$ past smoking behaviour is considered to be an important predictor for lung cancer rates. ${ }^{3} 7$ The accuracy of lung cancer projections can, therefore, be improved if historical data on smoking exposure in the population are incorporated into the models. This is likely to be particularly important if smoking trends peak and then reverse over time, as has occurred in a number of high-income countries, ${ }^{126}$ since the simple projection of lung cancer trends based only on data reflecting the burgeoning epidemic will not reflect the impact of a turnaround in smoking prevalence. ${ }^{3}$ However, our review found that only a very limited number of published studies incorporated smoking data in the projection models, with only eight studies including detailed historical data on smoking exposure along with lung cancer data in their projection models. ${ }^{3733103106108111112}$ Another eight studies used less detailed information or a limited amount of smoking data, which was not directly included in the projection models. ${ }^{41} 42102104105107109110$ Negri et al developed a method to incorporate smoking patterns into an APC model, multiplying the estimated period parameters by predefined coefficients based on recent trends in smoking prevalence and the tar yield of cigarettes. ${ }^{41} 42$ Two studies reported projections adjusted for the SAF, which involved modelling projections based on observed cancer data and then modifying the projected rates by multiplying by the SAF, which was estimated from a previous population-based study. ${ }^{102} 107$ This method can be used for data from any country where lung cancer is primarily caused by smoking, ${ }^{107}$ but is more suitable for countries where lung cancer mortality for males had reached its peak some time ago and recent smoking prevalence is similar for males and females. ${ }^{107}$ In addition, it should be noted that the SAF based on the relative risk of death for current smokers estimated by the American Cancer Society's Cancer Prevention Study II (ACS CPS-II) in the USA may not be applicable to other countries. ${ }^{107}$ 
A few other studies used methods which were based on cancer rates reported in the literature or on less detailed data, ${ }^{104105109}$ these methods are useful for countries where it is not realistic to use more sophisticated models due to the lack of detail in the available cancer and smoking data. However, for projections in populations at an earlier stage in the smoking epidemic more detailed information on tobacco exposure would be necessary so that the complex changes over time in the smoking behaviour of the population are captured. ${ }^{127}$

As previously discussed, GLMs are flexible and can be extended to incorporate other covariates, including smoking exposure, at the requisite level of detail. Log-linear models assuming a Poisson distribution based on age, cohort and cigarette tar exposure were reported by Brown and Kessler $^{3}$ using data from the USA, and by Shibuya $e t a l^{7}$ using data for four countries-the USA, UK, Canada and Australia. Both studies were based on sex-specific tobacco consumption over time for two large age groups (30-49 years and $\geq 50$ years) ${ }^{3}{ }^{37}$ These studies take into account the effects of changes in tobacco consumption and differences in exposure among birth cohorts, and both studies demonstrated improvements in projections by incorporating tar exposure measurements into the projection models. This approach was also reported by Knorr-Held and Rainer ${ }^{33}$ using data from Germany, but they concluded that the available smoking data in Germany were not able to improve their projections, because there was no available information on sex-specific cigarette consumption, nor on the average tar content per cigarette. This confirmed that accurate projections and the selection of appropriate projection methods depend on the quality and availability of data at the requisite level of detail. Some other smoking-related variables have also been used, including smoking intensity ${ }^{103108}$ and the number of years of smoking prior to age $40 .{ }^{106}$ All the studies using GLMs did not include constraints on the period and cohort components. This method has the advantage of flexibility and is able to piecewise examine the performance of various models based on different covariates, which is particularly relevant when detailed data on risk factors are available. However, the application of this method for a specific cancer type requires reasonable justification and validation, to ensure that the covariates included in the projection model are sufficient to reflect the factors that impact cancer rates in the population. In addition, the potential risk of ecological bias should be considered.

The availability of suitable software is paramount when dealing with complex models and inferences, such as when using APC models. The increasing number of studies using APC models is likely to be due to recent developments in statistical software packages including $\mathrm{R}$ and Stata. Norpred is a free-software package in $\mathrm{R}$ and S-PLUS for APC modelling which was developed by Møller et al at the Cancer Registry of Norway. ${ }^{10}$ It incorporates a smoothing technique and has become the most commonly used software for fitting APC models in recent years. However, Norpred only provides projections for a maximum of 25 years beyond the observed data, and no other covariates can be incorporated into the model. Other R packages, including 'Epi', 'apc'123 and 'INLA' ${ }^{48}$ can also be used for cancer incidence or mortality projections. Two packages in Stata were developed for APC models in the early 2010s and have the advantage of more flexible modelling implementation, ${ }^{122} 124$ although one package requires additional programming when projecting beyond the observed data. ${ }^{122}$ Joinpoint $^{118}$ is another popular package that has been increasingly used to project cancer rates into the future by extrapolating the most recent trend. ${ }^{128}$ However, Joinpoint is only considered to be suitable for short-term projections. ${ }^{118}$

We acknowledge that each method included in this review has its own merits and limitations depending on the length of projections, data quality and availability, and the timing of analysis in relation to different stages of the smoking epidemic in a country (particularly, whether smoking prevalence is assumed to peak over the time frame of the analysis). It is important to note that all projections of cancer incidence and mortality based on historical trends may be inaccurate, regardless of the method used, if the underlying trends in risk or interventions change. ${ }^{9}$ This is particularly relevant to lung cancer due to its strong relationship with tobacco exposure. ${ }^{8}$ There is no way to identify the 'best model' for all situations or to conclude that one method is superior to another. Furthermore, even projections using the same method can be sensitive to the model setting and the length of the projection base. ${ }^{10}$ Therefore, wherever possible, appropriate validation of the selected projection method should be performed, as such information is useful for checking the specifications of the model and helps researchers understand the potential limitations of the projection model. Performing a validation of the model being used for a projection by withholding the most recent observed data from the model fitting and then comparing the projected with the observed rates for the most recent period, can provide important information on the performance of the projection model. ${ }^{7}$ Surprisingly, however, fewer than $12 \%$ of the studies reported on this, although as highquality data on lung cancer rates is now available for several decades or longer for many countries it is likely that this type of validation will become more feasible and more frequently performed. In addition, as more data become available over time, prior statistical projections can be compared against the emergent data, which will allow for even greater understanding of the general strengths and pitfalls of the various methods-this exercise is underway and will yield further insights.

\section{Strengths and weaknesses}

Although we searched multiple electronic databases (Medline, Embase and PreMEDLINE databases), this review is limited to studies published in English. Thus, this review may not be complete if there were relevant studies published in other languages. It is also possible 
that we may have missed articles in the initial search, as we were unable to search the grey literature completely for eligible studies. It should also be noted that this review is limited to lung cancer only (International Classification of Diseases 10th Revision, ICD 10C33-C34), which means it will not capture the literature on every possible type of cancer related to the lungs (eg, mesothelioma). In addition, the wide variability in study populations and time periods made meta-analyses infeasible. Despite these potential limitations, we believe this review is still a valuable resource and has many strengths. By searching the reference lists of all included articles, we should have ensured a thorough and extensive coverage of the literature, and developing prespecified assessment criteria to provide clear definitions for the different assessment areas allowed for objective assessment of the studies. Also, a pretested and revised standardised form was used for data extraction, which should have minimised differences between the data extraction by different reviewers, as confirmed by the high agreement for the data extracted by the two reviewers (91.6\%). Also, we developed an organisational framework to categorise and summarise the projection methods used in the literature, which provides the comprehensive information and highlights the similarities and differences across methods. To our knowledge, this systematic review is the first to provide comprehensive, up-to-date coverage of the literature on statistical methods for projecting lung cancer rates.

\section{Implications for research}

This systematic review provides a comprehensive summary of the statistical methods over the past three decades used in published lung cancer incidence or mortality projections. The assessment of the strengths and advantages of existing methods will help researchers to better understand the currently used statistical methods for projecting lung cancer rates. In this review, we summarised both theoretical and practical aspects, including software information and generalisability of the methods, and some of the common methods described in this review can be applied to other cancer types, so it is hoped that this review will serve as a resource for researchers who are interested in using or developing one or more of these methods for projecting cancer rates. In particular, the methods incorporating a covariate such as smoking may be also applicable to projection of rates for other cancers with data on risk factors or diagnostic factors at the requisite level of detail, such as prostate specific antigen (PSA) testing rates for prostate cancer.

Acknowledgements We would like to thank Clare Kahn for editorial assistance, Harriet Hui for assistance in collecting full-text articles, and Victoria Freeman for assistance in updating the final search for this review.

Contributors All authors contributed substantially to the conception and design of the study. KC and DLO conceived the study. SH, QL and XQY drafted the study protocol and designed the data extraction form with input from DLO. SH did the initial scan of the literature search results to exclude articles that were clearly irrelevant. XQY, QL and DLO acted as reviewers. XQY and QL conducted the data extraction, data analysis and drafted the initial manuscript. DLO contributed to the interpretation of results and drafting of the manuscript. SW and MC contributed to the interpretation of results. All authors critically reviewed the manuscript and approved the final version.

Funding This project has not received any funding and the authors are employed by Caner Council NSW, Australia.

Competing interests None declared.

Patient consent for publication Not required.

Provenance and peer review Not commissioned; externally peer reviewed.

Data availability statement All data relevant to the study are included in the article or uploaded as online supplementary information.

Open access This is an open access article distributed in accordance with the Creative Commons Attribution Non Commercial (CC BY-NC 4.0) license, which permits others to distribute, remix, adapt, build upon this work non-commercially, and license their derivative works on different terms, provided the original work is properly cited, appropriate credit is given, any changes made indicated, and the use is non-commercial. See: http://creativecommons.org/licenses/by-nc/4.0/.

\section{REFERENCES}

1. Ferlay J, Soerjomataram I, Ervik M, et al. GLOBOCAN 2012 v1.0, Cancer incidence and mortality worldwide: IARC CancerBase No. 11 Lyon, France: International Agency for Research on Cancer, 2013. Available: http://globocan.iarc.fr

2. Bashir SA, Estève J. Projecting cancer incidence and mortality using Bayesian age-period-cohort models. J Epidemiol Biostat 2001;6:287-96.

3. Brown CC, Kessler LG. Projections of lung cancer mortality in the United States: 1985-2025. J Natl Cancer Inst 1988;80:43-51.

4. Doll R, Hill AB. Smoking and carcinoma of the lung. BMJ 1950;2:739-48.

5. Doll R, Peto R. Cigarette smoking and bronchial carcinoma: dose and time relationships among regular smokers and lifelong nonsmokers. J Epidemiol Community Health 1978;32:303-13.

6. Hakulinen T, Hakama M. Predictions of epidemiology and the evaluation of cancer control measures and the setting of policy priorities. Soc Sci Med 1991;33:1379-83.

7. Shibuya K, Inoue M, Lopez AD. Statistical modeling and projections of lung cancer mortality in 4 industrialized countries. Int $J$ Cancer 2005;117:476-85.

8. Bray F, Møller B. Predicting the future burden of cancer. Nat Rev Cancer 2006;6:63-74.

9. Cancer Projections Network. Long-Term projection methods: comparison of age-period-cohort model-based approaches. Alberta Health Services, 2010.

10. Møller B, Fekjaer H, Hakulinen T, et al. Prediction of cancer incidence in the Nordic countries: empirical comparison of different approaches. Stat Med 2003;22:2751-66.

11. Smith TR, Wakefield J. A review and comparison of age-periodcohort models for cancer incidence. Statist Sci 2016;31:591-610.

12. Moher D, Liberati A, Tetzlaff J, et al. Preferred reporting items for systematic reviews and meta-analyses: the PRISMA statement. PLoS Med 2009;6:e1000097.

13. Higgins JPT, Green S, eds. Cochrane Handbook for Systematic Reviews of Interventions Version 5.1.0 [updated March 2011]. The Cochrane Collaboration, 2011. Available: www.handbook.cochrane. org

14. Deeks J, Dinnes J, D'Amico R, et al. Evaluating non-randomised intervention studies. Health Technol Assess 2003;7:1-173.

15. Cancer Incidence in Five Continents. In: Forman D, Bray F, Brewster DH, et al, eds. IARC Scientifc Publication No 164. Lyon: International Agency for Research on Cancer, 2014.

16. United Nations Development Programme (UNDP). Human development report 2016, human development for everyone. Washington DC, USA: Communications Development Incorporated, 2016.

17. Alonso R, Piñeros M, Laversanne M, et al. Lung cancer incidence trends in Uruguay 1990-2014: an age-period-cohort analysis. Cancer Epidemiol 2018;55:17-22.

18. Bosetti C, Malvezzi M, Rosso T, et al. Lung cancer mortality in European women: trends and predictions. Lung Cancer 2012;78:171-8.

19. Cayuela A, Rodríguez-Dominguez S, López-Campos JL, et al. Lung cancer mortality in Spain: estimating the future burden to the year 2028. int $j$ tuberc lung dis 2011;15:1117-21. 
20. Chen W-Q, Zheng R-S, Zeng H-M. Bayesian age-period-cohort prediction of lung cancer incidence in China. Thoracic Cancer 2011;2:149-55.

21. Clements MS, Armstrong BK, Moolgavkar SH. Lung cancer rate predictions using generalized additive models. Biostatistics 2005;6:576-89.

22. Clèries R, Buxó M, Martínez JM, et al. Contribution of changes in demography and in the risk factors to the predicted pattern of cancer mortality among Spanish women by 2022. Cancer Epidemiol 2016;40:113-8

23. Clèries R, Ameijide A, Marcos-Gragera $R$, et al. Predicting the cancer burden in Catalonia between 2015 and 2025: the challenge of cancer management in the elderly. Clin Trans/ Oncol 2018;20:647-57.

24. Coupland VH, Okello C, Davies EA, et al. The future burden of cancer in London compared with England. $J$ Public Health 2010;32:83-9.

25. Eilstein D, Uhry Z, Lim TA, et al. Lung cancer mortality in France. trend analysis and projection between 1975 and 2012, using a Bayesian age-period-cohort model. Lung Cancer 2008;59:282-90.

26. Eilstein D, Eshai K. Lung and breast cancer mortality among women in France: future trends. Cancer Epidemiol 2012;36:e341-8.

27. Ferlay J, Parkin DM, Steliarova-Foucher E. Estimates of cancer incidence and mortality in Europe in 2008. Eur J Cancer 2010;46:765-81.

28. Ferlay J, Steliarova-Foucher E, Lortet-Tieulent J, et al. Cancer incidence and mortality patterns in Europe: estimates for 40 countries in 2012. Eur J Cancer 2013;49:1374-403.

29. Galasso R, Capocaccia R, Del Riccio L, et al. Estimates of cancer burden in Basilicata and Calabria. Tumori 2013;99:390-8.

30. Hristova L, Dimova I, Iltcheva M. Projected cancer incidence rates in Bulgaria, 1968-2017. Int J Epidemiol 1997;26:469-75.

31. Jürgens V, Ess S, Cerny T, et al. A Bayesian generalized ageperiod-cohort power model for cancer projections. Stat Med 2014;33:4627-36.

32. Kaneko S, Ishikawa KB, Yoshimi I, et al. Projection of lung cancer mortality in Japan. Cancer Sci 2003;94:919-23.

33. Knorr-Held L, Rainer E. Projections of lung cancer mortality in West Germany: a case study in Bayesian prediction. Biostatistics 2001;2:109-29.

34. Kubík A, Plesko I, Reissigová J. Prediction of lung cancer mortality in four central European countries, 1990-2009. Neoplasma 1998:45:60-7.

35. Li M, Wang S, Han X, et al. Cancer mortality trends in an industrial district of Shanghai, China, from 1974 to 2014 , and projections to 2029. Oncotarget 2017;8:92470-82.

36. Malvezzi M, Bosetti C, Rosso T, et al. Lung cancer mortality in European men: trends and predictions. Lung Cancer 2013;80:138-45.

37. Mistry M, Parkin DM, Ahmad AS, et al. Cancer incidence in the United Kingdom: projections to the year 2030. Br J Cancer 2011;105:1795-803.

38. Møller B, Fekjaer H, Hakulinen T, et al. Prediction of cancer incidence in the Nordic countries up to the year 2020. Eur J Cancer Prev 2002;11(Suppl 1):S1-96.

39. Møller B, Weedon-Fekjær H, Haldorsen T. Empirical evaluation of prediction intervals for cancer incidence. BMC Med Res Methodol 2005;5:21.

40. Møller H, Fairley L, Coupland V, et al. The future burden of cancer in England: incidence and numbers of new patients in 2020. Br J Cancer 2007:96:1484-8.

41. Negri E, La Vecchia C, Decarli A, et al. Projections to the end of the century of mortality from major cancer sites in Italy. Tumori 1990;76:420-8.

42. Negri E, La Vecchia C, Levi F, et al. The application of age, period and cohort models to predict Swiss cancer mortality. J Cancer Res Clin Oncol 1990;116:207-14.

43. Nowatzki J, Moller B, Demers A. Projection of future cancer incidence and new cancer cases in Manitoba, 2006-2025. Chronic Dis Can 2011;31:71-8.

44. Olsen AH, Parkin DM, Sasieni P. Cancer mortality in the United Kingdom: projections to the year 2025. Br J Cancer 2008;99:1549-54.

45. Pompe-Kirn V, Japelj B, Primic-Žakelj M. Future trends in breast, cervical, lung, mouth and pharyngeal cancer incidence in Slovenia. Cancer Causes Control 2000;11:309-18.

46. Rapiti E, Guarnori S, Pastoors B, et al. Planning for the future: cancer incidence projections in Switzerland up to 2019. BMC Public Health 2014;14:102.
47. Reissigova J, Luostarinen T, Hakulinen T, et al. Statistical modelling and prediction of lung cancer mortality in the Czech and Slovak Republics, 1960-1999. Int J Epidemiol 1994;23:665-72.

48. Ribes J, Esteban L, Clèries R, et al. Cancer incidence and mortality projections up to 2020 in Catalonia by means of Bayesian models. Clin Transl Oncol 2014;16:714-24.

49. Riebler A, Held L. Projecting the future burden of cancer: Bayesian age-period-cohort analysis with integrated nested Laplace approximations. Biom J 2017;59:531-49.

50. Rutherford MJ, Thompson JR, Lambert PC. Projecting cancer incidence using age-period-cohort models incorporating restricted cubic splines. Int J Biostat 2012;8:1-25.

51. Sánchez MJ, Payer T, De Angelis R, et al. Cancer incidence and mortality in Spain: estimates and projections for the period 19812012. Ann Oncol 2010;21(Suppl 3):iii30-6.

52. Sharp L, Black RJ, Muir CS, et al. Will the Scottish cancer target for the year 2000 be met? The use of cancer registration and death records to predict future cancer incidence and mortality in Scotland. Br J Cancer 1996;73:1115-21.

53. Smittenaar CR, Petersen KA, Stewart K, et al. Cancer incidence and mortality projections in the UK until 2035. Br J Cancer 2016:115:1147-55.

54. Son M, Yun J-W. Cancer mortality projections in Korea up to 2032. J Korean Med Sci 2016;31:892-901.

55. Stracci F, Petrucci MS, Ciampichini R, et al. Estimates of cancer burden in Umbria. Tumori 2013;99:342-50.

56. Swaminathan R, Shanta V, Ferlay J, et al. Trends in cancer incidence in Chennai city (1982-2006) and statewide predictions of future burden in Tamil Nadu (2007-16). Natl Med J India 2011;24:72-7.

57. Virani S, Bilheem S, Chansaard W, et al. National and subnational population-based incidence of cancer in Thailand: assessing cancers with the highest burdens. Cancers 2017:9:250.

58. Weir HK, Thompson TD, Soman A, et al. The past, present, and future of cancer incidence in the United States: 1975 through 2020. Cancer 2015;121:1827-37.

59. Australian Institute of Health Welfare. Cancer incidence projections Australia, 2011 to 2020. Canberra: AlHW, 2012.

60. Bray F, Jemal A, Grey N, et al. Global cancer transitions according to the human development index (2008-2030): a population-based study. Lancet Oncol 2012;13:790-801.

61. Brenner H, Ziegler H. Monitoring and projecting cancer incidence in Saarland, Germany, based on age-cohort analyses. J Epidemiol Community Health 1992:46:15-20.

62. Byers T, Barrera E, Fontham ETH, et al. A midpoint assessment of the American cancer Society challenge goal to halve the U.S. cancer mortality rates between the years 1990 and 2015. Cancer 2006;107:396-405.

63. Cancer Institute NSW. Cancer incidence and projections 20112021, 2016.

64. Carson CA, Zucconi SL. Health status indicators for the year 2000: projections for Allegheny County, Pennsylvania. Public Health Rep 1993;108:711-5.

65. Castro C, Antunes L, Lunet N, et al. Cancer incidence predictions in the North of Portugal: keeping population-based cancer registration up to date. Eur J Cancer Prev 2016;25:472-80.

66. Didkowska J, Wojiechowska U, Zatoriski W. Prediction of cancer incidence and mortality in Poland up to the year 2025. Warsaw: National Programme of Cancer Prevention, 2009.

67. Dušek L, Pavlík T, Májek O, et al. Estimating cancer incidence, prevalence, and the number of cancer patients treated with antitumor therapy in 2015 and 2020 - analysis of the Czech National Cancer Registry. Klin Onkol 2015;28:30-43.

68. Dyba T, Hakulinen T, Päivärinta L. A simple non-linear model in incidence prediction. Stat Med 1997;16:2297-309.

69. Dyba T, Hakulinen T. Comparison of different approaches to incidence prediction based on simple interpolation techniques. Stat Med 2000;19:1741-52.

70. Engeland A, Haldorsen T, Tretli S, et al. Prediction of cancer mortality in the Nordic countries up to the years 2000 and 2010, on the basis of relative survival analysis. A collaborative study of the five Nordic cancer registries. APMIS Suppl 1995;49:1-161.

71. French D, Catney D, Gavin AT. Modelling predictions of cancer deaths in Northern Ireland. Ulster Med J 2006;75:120-5.

72. Fukuda $\mathrm{Y}$, Nakamura K, Takano T. A combination of an extrapolation method and a benchmark method to develop quantitative health targets for Japan. Health Policy 2002;61:201-12.

73. Godlewski D, Wojtyś P, Antczak A. Predictions of cancer incidence in Wielkopolska in 2018. Wo 2012;1:38-43.

74. Hakulinen T, Dyba T. Precision of incidence predictions based on Poisson distributed observations. Stat Med 1994;13:1513-23. 
75. Heinävaara S, Hakulinen T. Predicting the lung cancer burden: accounting for selection of the patients with respect to general population mortality. Stat Med 2006;25:2967-80.

76. Jee Set al. Projected mortality from lung cancer in South Korea, 1980-2004. Int J Epidemiol 1998;27:365-9.

77. Kuroishi T, Hirose K, Tominaga S, et al. Prediction of future cancer mortality in Japan. Jpn J Clin Oncol 1992;22:365-9.

78. Malvezzi M, Bertuccio P, Rosso T, et al. European cancer mortality predictions for the year 2015: does lung cancer have the highest death rate in Eu women? Ann Oncol 2015;26:779-86.

79. Martín-Sánchez JC, Clèries R, Lidón C, et al. Bayesian prediction of lung and breast cancer mortality among women in Spain (20142020). Cancer Epidemiol 2016;43:22-9.

80. Oberaigner W, Geiger-Gritsch S. Prediction of cancer incidence in Tyrol/Austria for year of diagnosis 2020. Wien Klin Wochenschr 2014;126:642-9.

81. Olajide OO, Field JK, Davies MMPA, et al. Lung cancer trend in England for the period of 2002 to 2011 and projections of future burden until 2020. Int J Oncol 2015;47:739-46.

82. O'Lorcain $\mathrm{P}$, Comber $\mathrm{H}$. Lung cancer mortality predictions for Ireland 2001-2015 and current trends in North Western Europe. Lung Cancer 2004;46:157-63.

83. Parsons NR, Somervaille L. Estimation and projection of population lung cancer trends (United Kingdom). Cancer Causes Control 2000;11:467-75.

84. Shamseddine A, Saleh A, Charafeddine M, et al. Cancer trends in Lebanon: a review of incidence rates for the period of 2003-2008 and projections until 2018. Popul Health Metr 2014;12:4.

85. Torres-Avilés F, Moraga T, Núñez L, et al. Lung cancer mortality trends in Chile and six-year projections using Bayesian dynamic linear models. Cad Saude Publica 2015;31:1975-82.

86. Tsoi KKF, Hirai HW, Chan FCH, et al. Cancer burden with ageing population in urban regions in China: projection on cancer registry data from World Health organization. Br Med Bull 2017;121:83-94.

87. Wiklund K, Hakulinen T, Sparén P. Prediction of cancer mortality in the Nordic countries in 2005: effects of various interventions. Eur $J$ Cancer Prev 1992;1:247-58.

88. Yang L, Parkin DM, Ferlay J, et al. Estimates of cancer incidence in China for 2000 and projections for 2005. Cancer Epidemiol Biomarkers Prev 2005;14:243-50.

89. Yang L, Parkin DM, Li LD, et al. Estimation and projection of the National profile of cancer mortality in China: 1991-2005. Br J Cancer 2004;90:2157-66.

90. Baade PD, Meng X, Sinclair C, et al. Estimating the future burden of cancers preventable by better diet and physical activity in Australia. Med J Aust 2012;196:337-40.

91. D'Souza NDR, Murthy NS, Aras RY. Projection of burden of cancer mortality for India, 2011-2026. Asian Pac J Cancer Prev 2013;14:4387-92.

92. D'Souza NDR, Murthy NS, Aras RY. Projection of cancer incident cases for India -till 2026. Asian Pac J Cancer Prev 2013;14:4379-86.

93. Pearce A, Bradley C, Hanly P, et al. Projecting productivity losses for cancer-related mortality 2011 - 2030. BMC Cancer 2016;16:804.

94. Pisani P, Parkin DM, Ferlay J. Estimates of the worldwide mortality from eighteen major cancers in 1985. Implications for prevention and projections of future burden. Int. J. Cancer 1993;55:891-903.

95. Quante AS, Ming C, Rottmann M, et al. Projections of cancer incidence and cancer-related deaths in Germany by 2020 and 2030. Cancer Med 2016;5:2649-56.

96. Rahib L, Smith BD, Aizenberg R, et al. Projecting cancer incidence and deaths to 2030: the unexpected burden of thyroid, liver, and pancreas cancers in the United States. Cancer Res 2014;74:2913-21.

97. Smith BD, Smith GL, Hurria A, et al. Future of cancer incidence in the United States: burdens upon an aging, changing nation. J Clin Oncol 2009;27:2758-65.

98. Vardanjani HM, Zeinali M, Radmerikhi S, et al. Lung cancer prevalence in Iran by histologic subtypes. Adv Biomed Res 2017;6:111.

99. Yabroff KR, Bradley CJ, Mariotto AB, et al. Estimates and projections of value of life lost from cancer deaths in the United States. J Natl Cancer Inst 2008;100:1755-62.

100. Malvezzi M, Carioli G, Bertuccio P, et al. European cancer mortality predictions for the year 2018 with focus on colorectal cancer. Ann Oncol 2018;29:1016-22.
101. Martín-Sánchez JC, Lunet N, González-Marrón A, et al. Projections in breast and lung cancer mortality among women: a Bayesian analysis of 52 countries worldwide. Cancer Res 2018;78:4436-42.

102. Davis VN, Lavender A, Bayakly R, et al. Using current smoking prevalence to project lung cancer morbidity and mortality in Georgia by 2020. Prev Chronic Dis 2013;10:E74.

103. Murray CJL, Lopez AD. Alternative projections of mortality and disability by cause 1990-2020: global burden of disease study. Lancet 1997;349:1498-504.

104. Ng N, Winkler V, Van Minh $\mathrm{H}$, et al. Predicting lung cancer death in Africa and Asia: differences with who estimates. Cancer Causes Control 2009;20:721-30.

105. Pierce JP, Thurmond L, Rosbrook B. Projecting international lung cancer mortality rates: first approximations with tobaccoconsumption data. J Natl Cancer Inst Monogr 1992;12:45-9.

106. Preston SH, Stokes A, Mehta NK, et al. Projecting the effect of changes in smoking and obesity on future life expectancy in the United States. Demography 2014;51:27-49.

107. Stoeldraijer L, Bonneux L, van Duin C, et al. The future of smokingattributable mortality: the case of England \& Wales, Denmark and the Netherlands. Addiction 2015;110:336-45.

108. Strong K, Mathers C, Epping-Jordan J, et al. Preventing cancer through tobacco and infection control: How many lives can we save in the next 10 years? Eur J Cancer Prev 2008;17:153-61.

109. Winkler V, Mangolo NJ, Becher H. Lung cancer in South Africa: a forecast to 2025 based on smoking prevalence data. BMJ Open 2015;5:e006993.

110. Arslanhan S, Caner A, Helvacioglu K, et al. An economic analysis of tobacco elimination policies in turkey. Health Policy 2012;106:149-60.

111. Martín-Sánchez JC, Bilal U, Clèries R, et al. Modelling lung cancer mortality rates from smoking prevalence: fill in the gap. Cancer Epidemiol 2017;49:19-23.

112. Vogt T, van Raalte A, Grigoriev P, et al. The German EastWest mortality difference: two crossovers driven by smoking. Demography 2017;54:1051-71.

113. World Health Organization, Department of Information, Evidence and Research. Mortality database 2017.

114. Francis B, Green M, Payne C. The GLIM system: release 4 manual. Clarendon Press, 1993.

115. Spiegelhalter D, Thomas A, Best N. WinBUGS version 1.2 user manual. Cambridge: MRC Biostatistics Unit, 1999.

116. Martino S, Rue H. Implementing approximate Bayesian inference using integrated nested Laplace approximation: a manual for the inla program. Norway: Department of Mathematical Sciences, NTNU, 2009.

117. Schmid VJ, Held L. Bayesian age-period-cohort modeling and prediction - BAMP. J Stat Softw 2007;21:1-15.

118. Joinpoint Regression Program, Version 4.7.0.0 - June 2019. Statistical Methodology and Applications Branch, Surveillance Research Program, National Cancer Institute, 2017.

119. Stata Statistical Software: Release 13. College Station, TX: StataCorp LP, 2013

120. SAS software ${ }^{\circledR}$ Release 9.4 SAS Institute Inc. Cary, NC, USA, 2013

121. Kupper LL, Janis JM, Karmous A, et al. Statistical ageperiod-cohort analysis: a review and critique. J Chronic Dis 1985;38:811-30.

122. Rutherford M, Lambert P, Thompson J. Age-period-cohort modeling. The Stata Journal 2010;10:24.

123. Nielsen B. Apc: an R package for age-period-cohort analysis. $R J$ 2015;7:13.

124. Sasieni PD. Age-Period-Cohort models in Stata. Stata J 2012;12:45-60.

125. Dyba T, Hakulinen T. Do cancer predictions work? Eur J Cancer 2008;44:448-53.

126. Lopez AD, Collishaw NE, Piha T. A descriptive model of the cigarette epidemic in developed countries. Tob Control 1994;3:242-7

127. Thun M, Peto R, Boreham J, et al. Stages of the cigarette epidemic on entering its second century. Tob Control 2012;21:96-101.

128. Kim H-J, Fay MP, Feuer EJ, et al. Permutation tests for joinpoint regression with applications to cancer rates. Stat Med 2000;19:335-51. 